\title{
The Social Impact of Social Funds in Jamaica: A Mixed-Methods Analysis of Participation, Targeting and Collective Action in Community Driven Development
}

\author{
Vijayendra Rao, The World Bank, Washington DC \\ Ana María Ibáñez, Fedessarollo, Columbia
}

World Bank Policy Research Working Paper 2970, February 2003

The Policy Research Working Paper Series disseminates the findings of work in progress to encourage the exchange of ideas about development issues. An objective of the series is to get the findings out quickly, even if the presentations are less than fully polished. The papers carry the names of the authors and should be cited accordingly. The findings, interpretations, and conclusions expressed in this paper are entirely those of the authors. They do not necessarily represent the view of the World Bank, its Executive Directors, or the countries they represent. Policy Research Working Papers are available online at http:/lecon.worldbank.org.

We are grateful to Ruel Cooke and George Campbell for excellent fieldwork. This paper is the result of a joint OED-DEC data collection effort and we thank the OED team Soniya Carvalho, Anju Gupta Kapoor, Susan Razzaz and Howard White for their participation. We are grateful to Grace Imani Duncan for her input, and to Gershon Feder, Emmanuella Galasso, Errol George Graham, Martin Ravallion, Judith Tendler, Michael Woolcock and our colleagues in the Development Research Group for valuable comments and support, both moral and intellectual. The project was partially financed by Dutch and Norwegian Trust Funds. Please direct any correspondence to vrao@worldbank.org. 


\begin{abstract}
$\underline{\text { ABSTRACT }}$
The Social Impact of Social Funds in Jamaica: A Mixed-Methods Analysis of Participation, Targeting and Collective Action in Community Driven Development
\end{abstract}

Vijayendra Rao and Ana Maria Ibáñez

This paper develops an evaluation method that combines qualitative evidence with quantitative survey data analyzed with propensity score methods, on matched samples, to study the impact of a participatory community driven Social Fund on preference targeting, collective action, and community decision making. The data are from a case-study of five pairs of communities in Jamaica where one community in the pair has received funds from the Jamaica Social Investment Fund while the other has not - but has been picked to match the funded community in its social and economic characteristics. The qualitative data reveal that the social fund process is elite-driven and decision making tends to be dominated by a small group of motivated individuals. However, by the end of the project there is broad based satisfaction with the outcome. The quantitative data from 500 households mirror these findings by showing that ex-ante the social fund does not address the expressed needs of the majority of individuals in the majority of communities. By the end of the construction process, however, 80 per cent of the community expresses satisfaction with the outcome. An analysis of the determinants of participation demonstrates that better educated and better networked individuals dominate the process. Propensity score analysis reveals that JSIF has had a causal impact on improvements in trust and the capacity for collective action, but these gains are greater for elites within the community. Both JSIF and non-JSIF communities are more likely now to make decisions that affect their lives which is indicative of a broad based effort to promote participatory development in the country, but JSIF communities do not show higher levels of community driven decisions than non-JSIF communities. The evidence in this paper sheds light on the complex ways in which community driven development works inside communities -- a process that is deeply imbedded within Jamaica's socio-cultural and political context. 


\section{Introduction:}

Development assistance is becoming increasingly community-driven but there are still more questions than clear answers on how community driven development (CDD) really works. Does it improve participation and targeting? What kind of impact does it have? Does it build the capacity for collective action $^{1}$ ? One effective way on answering these important questions is by analyzing how the CDD process works inside communities, within their particular political, social and cultural systems. Previous research on CDD has tended to either use survey data from large samples or qualitative information from beneficiary assessments of communities that received projects. Both are limited in their ability to answer the questions posed above. Quantitative analysis can establish broad patterns of the impact of an intervention on poverty and well-being, but is less useful in understanding the institutional context within which CDD operates. Beneficiary assessments, on the other hand, can be very helpful in probing the social aspects of CDD but are subject to problems of selection bias, lack of generalizabilty, and are limited in their ability to establish the average causal impact of a project.

This paper will attempt to provide some answers to these questions by integrating quantitative and qualitative methods to conduct an in-depth analysis of data from five pairs of randomly selected communities in Jamaica. In each pair, one community has received assistance from the Jamaica Social Investment Fund (JSIF) a community driven project assisted by the World Bank, while its very similar matched counterpart has not received any assistance. Qualitative evidence from focus group discussions and in-depth interviews will draw out the institutional and cultural context within which the Social Fund process operates. It will sketch the various agents in the community, how leaders interacted with the community, and how the community perceived its gains from the project. Quantitative data will then be analyzed to evaluate the impact of social funds on measures of participation and collective action capacity using propensity score matching methods and regression analysis. This mixed method approach will permit a nuanced and contextualized understanding of the social fund process in Jamaica, while providing some evidence of the causal impact of the social fund on the social, political and economic life of individuals within the community. The in-depth data on social fund communities, however, is traded off with the size and representativeness of the sample and our findings should not be read as an evaluation of the JSIF portfolio of projects, but as an in-depth case study.

Social Investment Funds (SIFs) are perhaps the most visible mechanisms of CDD assistance, and a fast growing part of the World Bank's portfolio. A Social Fund is both an organization and a process.

\footnotetext{
${ }^{1}$ The capacity for collective action is a widely used definition of social capital (Woolcock and Narayan, 2001). However, social capital has so many other definitions that, for the sake of clarity, we will avoid using the term in this paper.
} 
Typically, it is a government agency that is set up as semi-independent institution reporting directly to the President or Prime Minister. Its role is to disburse grants directly to communities in order to fund the construction of a public good, with the communities contributing a small proportion of the costs (varying from 5 to 20 per cent), in cash, labor or materials. The key idea behind SIFs, and other mechanisms of community driven development, is that because communities participate in choosing projects themselves, the match between what a community needs and the project it receives is much better than in a traditional "top-down" development project. Several authors have also speculated that the process of applying and obtaining funds, and constructing and managing a facility, will improve the community's capacity for collective action (e.g.: Narayan and Ebbe 1997, Rao 2001). The belief is that this will in turn result in greater social cohesion, improve the community's ability to manage its own future and set it on a sustainable path towards poverty reduction

In recent months the literature on Community Driven Development, and Social Funds more specifically, has seen a spurt of growth. Conning and Kevane (2000) review the theoretical and empirical literature related to community based targeting (CBT), a specific type of CDD where the community assists in targeting poor families in order to transfer cash or food. They show that CBT possesses both positive and negative characteristics - the benefits include utilizing local information and the consequent potential improvement in targeting, but the risks are the increased opportunity of capture by elites within the community and the possibility that local preferences may not be egalitarian. Galasso and Ravallion (2001), look at this within the context of a CBT program in Bangladesh. They find that power within the community matters in how the funds are disbursed, but that targeting within the village improves with program size, lower inequality, proximity to the program office, among other things. Khwaja (2001) moves away from community based targeting to look at the community based provision of public goods in the Agha Khan Rural Support Project in Northern Pakistan. He finds that community participation in nontechnical decisions improves project maintenance, but that when communities get involved in technical decisions it results in worse projects. Repeating a theme emphasized in several papers (e.g. Abraham and Platteau 2001, Alesina et. al.) he finds that more heterogeneous communities are worse off, though better leadership seems to have a positive effect.

The literature that focuses more specifically on Social Funds is both critical and favorable. A quantitative impact evaluation (The Social Funds 2000 study) was recently conducted by the World Bank's Social Protection Unit using micro-data from several different countries (Van Domelen, 2001). Some highlights of the findings are as follows: An analysis of data based upon randomized trials in Bolivia found that SIFs had a positive impact on educational infrastructure but did not improve educational outcomes. However, health outcomes were improved with substantial declines in child mortality. Water projects also tended to improve access and quantity of water, but did not have an impact on water quality (Newman et. al. 
2001). Similarly an impact evaluation conducted in Zambia (Chase and Sherburne-Benz, 2001) found a positive impact on education and health. An extensive impact evaluation study conducted in Nicaragua also found a pro-poor bias with significant education and water-sanitation improvements (World Bank, 2000). Thus, the consensus view from Social Funds 2000 is that Social Funds are generally pro-poor both on the household level as well as geographically. Social Funds 2000 also reports that they are generally welfare improving. However, these quantitative studies do not have much to say on the impact of social funds on participation and collective action.

Evidence on these questions, to date, comes largely from Beneficiary Assessments, which are reports based usually upon Participatory Rural Appraisals (PRA) and Participatory Learning and Action tools (PLA) (Chambers, 1997), usually commissioned by the headquarters of a Social Fund, on targeted communities. They are not "impact evaluations" in the sense that they almost never include a control group or counter-factual to calculate the causal impact of the intervention. In a survey of Social Fund Beneficiary Assessments Owen and Von Domelen (1998) report that they were "uniform in their finding that beneficiaries consistently felt that social fund projects reflected priority needs of the community, confirming the essentially demand-driven nature of social funds." Owen and Von Domelen also report that the Beneficiary Assessments revealed a high degree of participation in the execution of projects. The Beneficiary Assessment for Jamaica provides a more complex picture of the relationship of the Jamaican Social Investment Fund (JSIF) to the communities it targets. Its overall findings, however, also are that JSIF has "succeeded to a large extent in its efforts to reduce poverty and increase social capital in targeted communities." Thus, the Bank's evaluations and assessments of Social Funds, on the whole, leave a favorable impression of an innovative process that not only is targeted to the poor, but is truly participatory with the capacity to build a community's capacity for collective action. This has led to sharp increases in lending to Social Fund and CDD projects, with a strong belief that CDD represents the future of development assistance.

Scholars outside the World Bank have tended to be more critical of SIFs and of the CDD process usually at the level of theory or by analyzing secondary data sources rather than examining survey data on CDD projects. Cornia (2001), focussing on the role of Social Funds as mechanisms to offset the anti-poor effects of structural adjustment programs, argues that they play only a minor role in assisting the “adjustment poor" and the "chronic poor." Tendler (1999, 2000), reviewing evidence from beneficiary assessment and project reports also argues that Social Funds tend to work better for communities that are less poor, and that they are vulnerable to mismanagement and political manipulation. She points out that the SIF model functions under a set of assumptions that have not been empirical tested - viz. that they are more responsive to consumer needs and preferences, and better tailored to local conditions. Importantly, she claims that many SIFs are actually supply driven rather than demand driven because choices of communities 
are not actually made by them. This claim is echoed by Abraham and Platteau (2001) who argue that CDD processes substantially privilege local elites over the less advantaged which leads to a "serious risk that development efforts are hijacked by unaccountable members of the elite." Abraham and Platteau focus on the structures of power and information within communities, arguing that the socio-cultural, political and economic context of the community within which the CDD project is being implemented is extremely important in determining its success or failure.

Community Driven Development and Social Investment Funds are, clearly, contentious topics with their advocates and detractors. While the evidence seems to indicate that Social Funds reach the poor and are relatively successful at improving service delivery, the assumptions under which they operate have still not been put to test. We do not know if SIFs are participatory: Do projects generated by SIFs meet the expressed preferences of the members of the community? Does the involvement of the community improve the community's capacity for collective action? Does the possibility of greater community involvement and ownership result in more sustainable facilities? These questions are best understood within the political, social and cultural life of communities within which CDD processes are deeply imbedded.

The Jamaican case-study analyzed in this paper will attempt to provide some answers to these questions, while providing an example of the use of mixed-method techniques to conduct an ex-post impact evaluation. The paper is organized as follows: In section 2 we will provide a brief history of Jamaica and its involvement in community led development, this will be followed in Section 3 with a an overview of the qualitative evidence from the five sets of communities. The findings from the qualitative evidence will then be tested for their generalizability with survey data, Section 4 will outline the methods used to analyze the survey data and the sampling methodology, section 5 will present the quantitative results, and section 6 will briefly review the qualitative and quantitative evidence to provide an integrated perspective and conclude the paper by summarizing the policy implications of the evidence. We should emphasize the paper should not be viewed as an evaluation of the Jamaica Social Investment Fund in its entirety. As a case study it benefits from the ability to examine five projects in some depth, but it also suffers from having a limited sample that lacks the scope to give a broad sense of JSIF's full portfolio of projects.

\section{The Historical Context:}

To understand how JSIF works, and how it is perceived in Jamaica, it helps to place within the context of Jamaican political history and culture. Modern Jamaican history is dominated by two cousins Norman Manley and Alexander Bustamante. Manley founded the People's National Party (PNP) in 1938 in an organized effort to end British rule. The PNP was closely associated with Bustamante's Industrial Trade 
Union (BITU). Bustamante broke away from the PNP in 1943 to form the Jamaica Labor Party (JLP) which, along with the PNP, would come to dominate Jamaica in the post-independence years.

The history of Community Driven Development in Jamaica is closely tied to Norman Manley and the PNP. The cooperative movement in Jamaica, which is the precursor to what is now called CDD, was pioneered by the Jamaica Welfare Society which Manley founded in 1937 with funds from a settlement over a labor dispute that he negotiated with multinational banana companies (Keith and Keith, 1992). The annual funds were to be used "not for charitable purposes... but for real help in the cultural development of the island and its peasants (p 7, Girvan, 1993). ${ }^{2}$ " The organization first focussed on building community centers to serve as "catalysts for rural development (Girvan, 1993)." By 1939 it had expanded its goals to foster "cooperation and self-help activities among the rural poor." The organization, over time, was considered extremely successful and has been called one of "Norman Manley's truly lasting contributions" (Keith and Keith, 1992). The Jamaican cooperative movement withered away in the 70's and 80's with the death of some of its prime movers like Norman Manley and D.T.M. Girvan - whom Manley had appointed as the head of the Jamaican Welfare Society in 1939. This paralleled the worldwide trend away from the cooperative movement towards development policies focussed more on top-down infrastructure and human capital projects, and the liberalization of internal markets and trade. By the early 1990's, however, interest in CDD had revived in Latin America as an antidote to the structural adjustment programs that characterized the 1980's with several countries establishing Social Funds.

In 1996, The Jamaican Social Investment Fund (JSIF) was instituted by the PNP government, now led by Percival James Patterson, and is perceived in Jamaica as the successor to the Jamaica Welfare Society. Its methods and objectives closely parallel those of the Welfare Society, and several (now quite elderly) participants in projects instituted by the Welfare Society play a key role in JSIF projects at the community level. JSIF stated goal is in "improving living standards for the poor and vulnerable." It has four key objectives -

-To establish an efficient, demand, driven and complementary mechanism to deliver basic services to the poor.

-To mobilize and channel additional resources to the areas of social assistance and basic social and economic infrastructure.

- To increase the institutional capacity of governmental and non-governmental entities to design, implement and manage small scale community based projects

- To empower communities by seeking to ensure greater levels of community involvement in development programs and community participation in decisions affecting their lives.

\footnotetext{
${ }^{2}$ Clearly "cultural" here was meant to include social and economic development.
} 
As one of the Social Funds in the Latin America and Caribbean region it has been clearly influenced in its methods and practices by experiences with Social Funds in countries such as Nicaragua, Ecuador and Zambia. JSIF should, however, also be seen within the context of Jamaica's history with the cooperative movement. The writings of D.T.M. Girvan, who led the Jamaica Welfare Society during most of its active years, and then advised the cooperative movement in Ecuador and Chile, provide an instructive window into the historical context of the CDD processes. One of the key foundations of his view was to "work together in groups to do those things which we as individuals cannot do." An excerpt from a paper he wrote in 1941 (Girvan 1993) on "The Better Community Approach to Community Development," shows how deeply embedded contemporary social fund practice is within the cooperative movement:

Building a Better Community depends first and foremost on the desire for citizens for selfimprovement. This desire may be found in most communities in varying degrees; in all it can be aroused and stimulated.

Care must, however, be taken before arousing this desire in any community to secure the cooperation of local "key" people and to gather basic information about the community. Key people would be individuals such as teachers and other public officers, ministers and clergy, and the voluntary leaders of existing community organizations as well as, perhaps, some of the citizens who wish to help or who possess influence that can be of service.

If a temporary Community Committee can be immediately formed from among these leaders, this would be an excellent start, as the objective is to have all community activities planned and coordinated by a Community Council comprised of representatives from existing community groups with co-opted members from amongst the citizens.

In any case, with the help of local leaders, a Social Survey should be undertaken which will provide salient facts about social and economic conditions, and existing community structures. Based on this, decisions will be taken about what can be done to encourage and to extend existing community organisations, and to help in arranging training for their leaders and in planning their programme along concrete lines, including the formation of practical projects.

These sixty year old guidelines seem to have had a clear influence in the manner in which the Jamaican Social Investment Fund (JSIF) currently operates. JSIF is an autonomous government agency that reports directly to the Ministry of Finance. It solicits proposals from communities by widely disseminating information via radio and television. NGOs, community based organizations (CBOs), and central government agencies facilitate the applications by helping key actors organize the community to decide on and apply for a project. These NGO, CBOs and key actors within communities often have a past association with the Jamaica Welfare Society and follow similar procedures. The proposal usually includes a social appraisal outlining the problems faced by the community, how this intersects with social and economic 
constraints within the community, and the role that a sub-project can play in improving living standards. JSIF screens the applications on the basis of its target criteria which mandate a focus on the poorest communities, and then undertakes a series of field visits to identify through research (e.g: PPAs, animation, sample surveys) a realistic sense of the needs of the community.

Like other Social Funds, communities are usually required to make a contribution to construction costs either in cash or in kind. Projects are supposed to be decided in broad consultation with the community and must fall within a menu of projects that JSIF will support. There are however, notable exceptions to this menu-based restriction as we will demonstrate below. The projects are generally executed by contractors employed by JSIF, and then managed by the appropriate ministry (e.g. Education, Health). It is expected that the community, having a greater sense of ownership of the project, will participate in its maintenance and management thus improving project sustainability.

Having seen a bit of the history and background of CDD in Jamaica and looked at JSIF's guidelines, let us now turn to an examination of how these guidelines work in practice.

\section{$\underline{\text { 2. Qualitative Analysis }}{ }^{3}$}

The qualitative data is based upon semi-structured in-depth interviews with several key players in each community: JSIF project coordinators, community leaders (elected officials, community elders, pastors, etc.), and members of the JSIF committee in each community who helped organize and manage the project. Three extended focus group discussions were also conducted in each community with groups of people who were, as far as possible, selected to represent the entire community. Data from these interviews is supplemented with observations from field visits by Ruel Cooke, one of the consultants who supervised the data collection, and Rao who conducted field visits in six of the ten communities in the sample. The report on Arnett Gardens is also supplemented by a report by Duncan (2001) commissioned for this paper, based upon several additional interviews with "Dons," politicians, and other men and women who live in the community.

We should note that the focus groups, in-depth interviews were not conducted on a random sample. Moreover, despite efforts to avoid the problem, it is possible that members of the community who participated in the focus group discussions were more likely to have participated actively in the social fund process. This could, potentially, result in biased findings. Therefore, the qualitative findings should not be examined on their own, but in conjunction with the survey results that are based upon a representative

\footnotetext{
3 The names of three of the five communities have been changed. Two communities, Port Royal and Arnett Gardens, are extremely well known and difficult to disguise. Furthermore, understanding the impact of JSIF project in them requires an understanding of their history. For these reasons we have retained their real names. The names of all the individuals quoted have also been changed with the exception of prominent people who would be difficult to disguise.
} 
random sample. The qualitative information is useful, however, to sketch a narrative of participation and collective action in the JSIF and non-JSIF communities. We will outline the key players, the manner in which community mobilization occurred, and the perceived impact of the project the in community. The non-JSIF community will also be very briefly sketched to provide a sense of the difference between the matched pairs.

\section{Community Pair A:}

Port Royal and Rennock Lodge

Port Royal is an old and historic town that was the capital of Jamaica when it was under Spanish rule. It subsequently became a haven for pirates and buccaneers. Most of the old Spanish town was submerged after a series of hurricanes and earthquakes in the $19^{\text {th }}$ century. The town also has a large fort dating from the $18^{\text {th }}$ century and has significant but underdeveloped potential as a tourist site. It is also a community that has over the years, through generations of inter-marriage, become extremely tight knit, but with clear divisions based upon class, status, religion, and political affiliation. The community is dominated by the Port Royal Brotherhood, a semi-governmental authority, which owns most of the public infrastructure and housing, and is considered akin to a local planning authority. Interestingly, the Port Royal Brotherhood was founded by D.T.M Girvan in 1952 as an arm of the Jamaican Welfare Society, but its foundations in the cooperative movement seem to have evolved into a more political function.

There is a clear split in the community between those loyal to the Brotherhood and those opposed to

it. In the last few years an arm of the local citizens association, functioning as an alternative to the Brotherhood, formed a development group known as the Port Royal Environmental Management Trust (PREMT) that has been spearheading an effort to bring in more developmental investment into the town. In particular they plan to develop the town as a port for cruise ships like the large tourist ports of Montego Bay and Ocho Rios. This has the potential to transform the town into an important tourist site.

PREMT were also responsible for initiating the JSIF proposal. They hired a consultancy firm called EduTech to develop the proposal and submit it to JSIF. The proposal, which was developed with limited community consultation, asked to have a computer center in the local school. The idea was that this center would benefit students during school hours but would also be used to instruct adults. PREMT works independently of, and perhaps even in opposition to the Brotherhood. In the words of a PREMT leader, "Us and them (the Brotherhood) don't get along." This indicates that the social fund application process may be at the center of the internal politics of the community. Contrary to the predictions of theories of participation, the divisions within the community are not a result of its heterogeneity - but a consequence of 
how tightly bound it is. Everyone seems to be everyone elses kin and, over the years, personal animosities and family conflicts appear to have spilled over into the community's internal decision making process. It is possible that PREMT's efforts at eliciting JSIF funds is an attempt to rival the Brotherhood's historical association with the Jamaican Welfare Society.

The Port Royal project provided a computer center for the school. The project was not participatory in the sense that a computer center was not a priority with most the members of the community who would have preferred a project that generated more employment. As described above, PREMT seems to have made the decision almost unilaterally, and the technical orientation of the project seems to have been influenced by the consultants (EDUTECH) chosen to help with writing the JSIF proposal. PREMT sees the center as part of an overall development plan for Port Royal and envisages a day when computer- trained members of the community will be able to get jobs at the resorts and other offices that they believe will come with the tourist influx. In this sense PREMT is acting as a local social planner - and the notion that community input and participation led to the choice of project is clearly not true in this case. Also, it is clear that the "traditional leadership" i.e.: The Brotherhood, was bypassed in the JSIF application. While this goes against JSIF guidelines, it seemed inevitable that in a community with deep divisions it would be very difficult for all factions to come to a common agreement on a project. Respondents in Port Royal, however, claim that other projects in the community - notably one conducted by "New Horizons," were much more participatory. In JSIF's favor they also say that JSIF, while less participatory, was also more transparent in keeping all transactions above board and communicating information about the project clearly to the community.

Note that despite the lack of widespread participation in the choice of project, there seems to be a lot of pride and support for the computer center within the community. Respondents said that this was the first concrete example of the much-vaunted changes that had been promised for many years by PREMT. There was also a general perception that school children were benefiting from the center, and in a visit that we made it was clear that there was excess demand for the use of the computers with children intently working and trying to maximize their time on them. The success of the project has caused some resentment among the adults in the community who believe that they too should be allowed to use the computers under an adult education program. Adults claimed that when the project was first proposed, they were told that adults would also be able to benefit from it. The fact that this has not happened has caused some resentment.

The project did seem to have a clear but limited impact on the community's ability to work together for common goals. This is a deeply fragmented community, but respondents said that they "managed to work together" even though "disputes are too deep." In visiting the community it was clear that those members who were not followers of the Brotherhood were more likely to express enthusiasm about the project and to express interest in mobilizing more projects in the community. One of the bases for the 
division was an inherent difference of opinion on whether the community should open up and widely embrace the tourist trade or whether it should attempt to resist the disruptive changes in social and community life that this would cause. The computer center had widespread support partly because it represented a positive, modern, change in a manner that did not lead to outside encroachment and thus had support from both groups.

It is difficult to find a community that is a close match with Port Royal, but Rennock Lodge comes reasonably close in that it is also is located on the sea and is an old community with many long term residents. However, Port Royal's unique history makes it different from every other community in Jamaica including Rennock Lodge. Rennock Lodge is also more "urban" than Port Royal in the sense that it is much closer to the capital city - Kingston and has some of the attendant social problems with gangs and youth unemployment.

Rennock Lodge is also different in that there seem to be no organizations or institutions providing leadership within it and no group appears to be making efforts to mobilize resources on behalf of the community. The leadership that exists does not seem to have wide support - respondents described resource allocation within the community as being characterized by the "paternalistic distribution of political patronage." Most community activities center around the football (soccer) club and the local Anglican Church. Like Port Royal, the community is socially and politically homogenous but it does not exhibit Port Royal's deep kin-based divisions.

To summarize, it is clear that the JSIF project brought a sense of common purpose to the Port Royal - many members of the community were able to see a concrete example of progress that was a signal of changes to come, though some were apprehensive of the impact those changes. There is also a feeling, however, that the benefits of the project have not been equitably distributed. Moreover, the sense of common purpose has not erased old divisions and in some ways the JSIF project may have even reinforced them.

\section{Community Pair B:}

Virginia and Downing

The second community we examine is Virginia, where JSIF funded the construction of a basic school (pre-school from ages 3-6). Virginia is a rural community where most residents are either small farmers or workers in the local sugar cane fields and coffee plantations. Community life is centered around the local Anglican Church, where one of the church elders Mr. Larry Jordan was the central player in mobilizing the community towards accessing development projects. Mr. Jordan is a deeply religious man who, many years ago, was associated with the Jamaica Welfare Society. 
Mr. Jordan is also the pivotal figure behind Virginia's JSIF assisted basic school project. Virginia had a school whose structure was severely damaged by Hurricane Gilbert in 1988. When Mr. Jordan came to hear about JSIF nine years later, he used the church and its leadership to mobilize the community to apply for funds to renovate the school. The community seems to have readily agreed to this, since the lack of a good school structure was obviously a pressing need. The fact that a good structure once existed, but had been damaged without any real repairs for several years was a motivating factor. The project seems to have been thoroughly cooperative and participatory - the community provided labor services and were given training to help with construction skills and management.

Teenagers and men and women in their 20's do, however, seem disengaged from these processes. They express resentment against the church and its central role in community life. Some wish to have a "youth center" that they would like to mobilize JSIF funds towards. Some of the resentment against the JSIF school project is a level of unhappiness that JSIF changed the management of the school, replacing an old, revered school principal with a new person who most in the community do not seem to like. This suggested that the greater sense of ownership that participation engineers may also lead to a greater desire to control the project after it is created with a greater say over its management. It is unclear that the same level of resentment would have been expressed with an old style development project.

Virginia has been matched with Downing - a community that is about a twenty minute drive away from Virginia - similar in its demographic characteristics and its church-centered social life. Downing has its own history with JSIF. It also has a school, which is in reasonably good shape, but suffers from constant vandalism by "disaffected youth." Teenagers tend to congregate in its grounds, play loud music, games, harass students and teachers, and throw rocks at windows. The teachers also expressed a fear of crime and violence because of this, but we were not able to detect any actual incidents of crime or violence around the premises of the school. Because of the vandalism, residents of Downing had applied to JSIF for some funds to build a gated fence around the school. JSIF rejected the proposal for reasons that are unclear.

In summary, JSIF seems to have had a largely positive impact in Virginia. There was a clearly a pressing need to renovate the basic school and the community was easily mobilized towards this end by a respected elder with experience in community-based development. The JSIF project seems to have created hope in the community for further projects and motivated them to seek further assistance.

\section{$\underline{\text { Community Pair C }}$}

New Valley/Orange - Shadow/California

JSIF funded a road that connected the communities of New Valley and Orange to a highway. Once again this project demonstrates the importance of the church in rural Jamaica, and its important role in 
community driven development. The project was initiated by the pastor Rev. Williams of New Valley who read about JSIF in the newspaper and mobilized church and community leaders to harness community support to apply for funds. Both communities, New Valley and Orange were involved in writing the application, and the project has benefited both communities - though arguably it has benefited New Valley more than Orange.

The "pastor was the leader" here. It was initially difficult to mobilize the community but Rev. Williams worked hard to get the process moving. Ultimately "no (monetary) contribution was required in the project so everyone participated" and voluntarily provided services like free labor and food. Despite the projects obvious benefits, residents of New Valley expressed some dissatisfaction with JSIF saying that the contractors did "shoddy work" and that employment on the project was not fairly distributed. On the choice of contractor they said, "because we are beggars we have to accept what JSIF gives us." The community was often consulted with several meetings held during the initial stages. This generated complaints of "too many meetings." But there was no consultation about the choice of contractor. Some resentment was also directed at Rev. Williams who, according to a focus group, "was thinking of his own convenience" by making sure that the road was extended till it "ended at the church." Once again we hear reports that youth are disaffected, and do not participate in community activities.

However, the project has had a "tremendously positive" impact on the life of the community. The road is a "lifeline" that allows residents to take their produce to the market, access taxis and other transportation to connect to the main arteries. It seems obvious that the road has had a transforming effect on the community's economic and social life. Residents told us that participating in the project developed a sense of "ecumenism" in the community. It has energized various local community associations that were lying dormant for several years. The community is enthused enough that they want to apply for more funds to extent the road even further. They also wish to look for funds for a school or a clinic.

Shadow/California is the matching pair of communities for New Valley/Orange. It is located in the same county as New Valley/Orange and has similar problems in that it suffers from the lack of a road, which cuts it off from the main Jamaican highways. This leads to several problems - high prices for water, lack of access to schools, and difficulty transporting cash crops. The community seems to have a sense that it is overlooked by its political representatives, a focus group discussion described themselves as a "rejected community."

Yet, the community, also deeply religious and centered around the church, has a high degree of social cohesion and is eager to participate in collective action for the common good. A focus group discussion on their work towards maintaining the unpaved road that now exists reveals this succinctly, "We work together for the good maintenance of the road because all of us need it. We filled it with cement and other materials. We worked on it by ourselves." "We had a benefit from the experience. We learned to 
work together." In fact, we recently received reports that the community had organized itself into protesting the lack of funds for a road by blocking one of Jamaica's main highways to bring attention to their plight. While not everyone would see this is as a constructive activity, it does indeed demonstrate a great deal of collective action capacity.

The data from these two sets of communities reveals that the social fund has clearly had a positive impact on New Valley/Orange by providing a desperately needed resource. While there was some resentment expressed against the project, this experience with collective action seems to have left the community thirsting for more.

\section{Community Pair D}

$\underline{\text { Arnett Gardens - Union Gardens }}{ }^{4}$

Arnett Gardens and Union Gardens are located in inner-city Kingston, Jamaica’s capital city and also its largest with almost half the country's population. Arnett Gardens where the JSIF project is located is known as a "garrison community." These are communities in Kingston that were founded and controlled by the PNP and the JLP. Arnett is a stronghold of the PNP. In order to understand the role of the JSIF project in these communities, it will help to briefly recount the history of violence and political conflict in inner-city Kingston.

Towards the end of the 1960's the first garrison community, Tivoli Gardens, was established by the JLP as part of what was called a "slum clearance project." Arnett Gardens was established in 1972-74 by the PNP to counter the influence of Tivoli Gardens. Partly as a result of political mobilization within Tivoli and Arnett Gardens, the 1970's saw a sharp increase in politically driven violence which prompted the then PNP Prime Minister Michael Manley to declare a State of Emergency in 1976. In 1978 Bob Marley, the reggae icon, attempted to bring the political parties together with the One Love Peace Concert, where Edward Seaga, the JLP leader, and Manley went on-stage with Marley and held hands together to symbolically mark a new era.

The One Love concert represents an important marker in Jamaican history, but was not associated with a reduction in political violence which peaked in the early 1980's. As the 80's progressed, however, the garrison communities became central locations for the drug trade primarily as a conduit for transporting marijuana and cocaine to the United States. Thus, the drug economy supplanted politics as the driving force behind violence and rival gangs, organized around the same boundaries as the garrisons, competed over the

\footnotetext{
${ }^{4}$ The Arnett Gardens report is based upon fieldwork conducted by Ruel Cooke for the JSIF evaluation, and a separate study by Grace Imani Duncan (2001) commissioned for this paper followed up by work by Duncan and Woolcock (2002).
} 
trade. By 1996-97, violence had reached the highest point in Jamaican history with homicides showing a 33 per cent increase between 1995 and 1997.

In 1996 a proposal was floated to reconstruct the Kingston Public Hospital, which is located close to the garrison communities and services people from inner-city Kingston. To facilitate the construction of the hospital, two of the most powerful Dons in Jamaica, Dudus (JLP) and Zekes (PNP) orchestrated a peace agreement in 1996. The agreement is better characterized as a strategic alliance carefully demarcating areas of control. Preliminary fieldwork seems to suggests that Zekes was allowed to control the areas bordering greater Kingston and thus access to jobs and other economic opportunities, while Dudus was granted control over the wharfs and therefore to the drug and gun trade (Duncan, 2001). The JSIF sponsored renovation of the Tony Spaulding Stadium in Arnett Gardens should be viewed within this context.

The JSIF effort began in 1996 when JSIF commissioned a study by a team of anthropologists to understand how public assistance could help alleviate the violence (Moser and Holland, 1997). On the basis of several in-depth interviews, PRA exercises and focus groups discussions, the anthropologists attempted to identify the complex socio-cultural, political and economic bases for the violence. Underlying all these factors, they said were two key causes -- the lack of jobs and the lack of cooperation and communication across communities. They, therefore suggested, as a priority, that JSIF assist in "rehabilitating and equipping integrated community spaces such as sports facilities, teen centers and training facilities," claiming that this would provide "a modest entry point to break contextually specific cycles of poverty and violence.." Given that JSIF typically sponsors projects related to schools, health clinics, roads, and water, constructing a sports facility was a radical departure from practice. Taking account of Moser and Holland's recommendations, Vision Development - a local NGO - applied to JSIF for funds to assist the rehabilitation of the Tony Spaulding Stadium which was an existing facility that was used primarily as a football field for the area teams. JSIF funded in the construction of bleachers, and in renovating locker rooms and training facilities. The goal was to make the Complex a center of inter-community sports activity.

There is little evidence that this was done in a participatory manner. Unlike Virginia or New Valley there was almost no direct community participation, aside from the social analysis, or community contribution and almost all the costs, planning and construction was borne by JSIF. There was a clear lack of information about the JSIF process in Arnett Gardens, and in fact almost no one we spoke was aware that the project was sponsored by JSIF. We were told that there was a lot of support for the project, about which the "community got together as a family," but, "nobody from the community worked on the project." There was some resentment expressed about this - a belief that the work was done by workers from outside when it was an obvious source of employment in a community that desperately needed jobs. All of this is clear evidence that JSIF had essentially given up following its participation guidelines here. This does not mean 
that JSIF made the wrong decision. Given the nature of the project and what it was trying to accomplish, one can imagine that it would have been particularly difficult to get the community to make contributions.

When this field work was conducted in March 2000, the sense we got was that the project had accomplished wonders. A focus group said, "the complex is a showpiece and offers a fantastic view of the community. It is a sign of progress as it adds to the overall development of the community and removes some of the stigma attached to it." Rao spent a day going from house to house asking questions about people's perceptions about the project and without exception, and without prompting, he was told that there was a huge drop in violence that residents directly attributed to the new stadium. "The kids play football instead of killing each other." "If there are more sporting activities the youths will have less time to think about guns." While Arnett Gardens, in March 2000, was still not a neighborhood where residents of Kingston would feel safe to roam around in, it no longer seemed like the war zone it used to be. Elderly men and women sat on their porches or gardens, children played cricket or soccer on the street. Contrast this with another nearby area - a few miles away - when one felt a clear sense of danger. Young men were roaming the streets with unsheathed knives stuck in their belts, guns were carried freely. Outsiders were stared at and were treated with suspicion.

Figure 1 which presents time series data on crime from Western Kingston, where the oldest and best established garrison communities are located, provides dramatic evidence of the decline in crime and violence. All types of crime have shown a decline here since 1996. This was prior to the JSIF intervention. Note however, that after 1997 crime violence declined at a steeper rate suggesting that JSIF may have provided some additional impetus to the process. Figure 2 provides evidence to show that the decline in violence in Western Jamaica is in sharp contrast to the rest of Jamaica where murder rates have remained relatively stable. Nevertheless it is important to not attribute all the declines in violence to the Tony Spaulding renovation but to see it as part of a concerted effort to reduce violence in the garrison communities.

Arnett Gardens remains one of the poorest neighborhoods in Kingston. A focus group discussion revealed, for instance that, "We are saddened by the fact that the community is mostly brought together by death, along with dances and sporting activities." Teenage pregnancy, unemployment, and the youth discontentment remain serious problems. It is still difficult to get the community to work together for the common good and political parties continue to define the neighborhoods. A community leader told us, "We need a community system, not a party system." "Leadership is dispersed between ...(various leaders). Some take care of security, and others take care of neighborhood needs."

Much of our findings from March 2000 need to be rethought in the wake of the events of July 2001, when intense violence flared up again in the garrison communities. While the annual murder rate is still not in, it is likely to soar again to the levels of the 90's indicating that the abatement in violence was more a lull 
than a cessation. As Jamaica drew closer to a general election in 2002, it appeared that traditional politically driven tensions were once again causing conflict. Therefore, the possible impact that the Tony Spaulding stadium project had on the community does not seem to have been sustained over the long term.

Furthermore, to the extent that the peace process caused a lull in the violence, it does not seem to have been a direct result of the stadium renovation as much as part of a broad peace initiative instituted between the two main warring factions in Kingston. Yet, there is also no question that the stadium has had a large and positive impact on the community in the sense that it is a symbol or pride and provides a valuable public service.

The matching community - Union Gardens is similar to Arnett gardens in its occupational structure and levels of poverty. Patterns of violence in Union Gardens mirror those in Arnett gardens indicating the lack of a causal link between the Tony Spaulding stadium initiative and the cessation of violence in the two communities. However, we were told in 2000 that Union Gardens is "as united as can be expected." They have a citizens association where most community-wide decisions are made. A leader told us that they "are the only community in the western belt (of Kingston) not warring against a neighboring one." $\mathrm{He}$ also told us that "Union Gardens in rejected by all." Thus, there is a clear sense that they have been abandoned perhaps amplified by the high profile interventions they see in places like Arnett Gardens.

To summarize, the Tony Spaulding stadium has had an impact on Arnett Gardens that is both symbolic and real. It represents an intervention that was preceded by some thought and analysis by JSIF, and participatory aspects seem to have been given up in favor of the more larger goal of doing something that would dramatically reduce violence. As a part of the peace initiatives instituted at the time of its conclusion, it seems to have played a part in the reduction in violence between 1999 and 2001 but its impact must be seen in the context of the extraordinary peace agreement arrived at between the two Dons, Zekes and Dudus, in 1996. However, the recent increase in politically driven violence in these communities suggests that peace was not sustainable over the long term. Long term peace would require a basic change in Jamaica's political culture which is, perhaps, an elusive goal (Keith and Keith, 1992).

\section{Community Pair E:}

\section{$\underline{\text { Rock Creek/Creighton }}$}

Rock Creek is located at the west end of Jamaica, close to the resort town of Negril and many of its residents commute to Negril to work in the tourist industry. Rock Creek had a basic school that was housed in a church building with a roof that was damaged by a hurricane. In 1997, even this dilapidated structure was destroyed by a fire. The fire motivated the community to seek JSIF funds to renovate the school building. The school principal instigated efforts to start the renovation under the auspices of the Sports 
Club, an organization largely consisting of younger members of the community. The Sports Club leadership then attempted to widen the base of support in the community enlisting the help of the church and by forming a Citizens Association with a group of interested parents. The Sports club leader says that the process of galvanizing the community around the project was not easy and "to ensure broad support for participation the community had to be educated about the project." "It was a difficult process, but through public education (the sports club) was able to the community totally involved." Ultimately, according the Sports Club leader, "the Church was not as actively involved as it was hoped."

The Citizens Association, on the other hand, raised a substantial amount of money from the community, even prior to the JSIF intervention. Once JSIF approved the project, it helped organized workdays, dug the foundation and built a driveway and parking area. It also played a key role in assisting the contractor to acquire building materials on credit from local hardware merchants. The community was, therefore, very actively involved in the project in all its phases. Their contribution far exceeded the minimum 5 per cent required by JSIF. This allowed enough funds to be left over a canteen to be constructed entirely out of community funds after the school was constructed.

The impact of the project on the community has been favorable though the prognosis is mixed. Focus group discussions seem to echo the rhetoric of participation. They say that have learned the "idea of a community learning to work together for the good of the entire communit y." They add that the project motivated "the community to work together for the good of everyone," and that "Team work is necessary to accomplish goals. The local Councilor tells us that "successful conclusion of the project served to strengthen the sense of community." However, the councilor also says that it has led to "rivalries" between the Sports Club, the church and the PTA. Furthermore, he is "not sure who is responsible for ongoing maintenance and operation." The Principal does not know whom to turn to for this and there is no school board in place and project committee's present role needs to be clarified. This leads to questions about how sustainable the project is. The Sports Club leader reiterates this point saying, "Currently there is confusion about who is responsible for the sustainability of the school." There is a "need for more community effort now that the project is completed to ensure that the building and grounds are properly maintained. Support can only be gotten if the community sees the benefits."

From all of this one gets the sense that the community was very well organized in obtaining funds for the project. There was a commonly felt need when the school was destroyed. One also gets the sense that the traditional leadership in the community did not make enough efforts to restore the school and this created space for the Sports Club to exercise leadership and mobilize the community. The JSIF process was clearly well suited to this purpose and Rock Creek, as a motivated, well-organized community obtained the funds easily. However, once the project was completed, there was clearly some confusion as to who is responsible for the facilities operation and maintenance. The normal procedure is for the School Board to 
take over these functions, but no such body was formed. Consequently there were some tensions between the Church - representing the traditional authority figures in the community, and the Sports Club, despite their central role in getting the project started, may be losing power in the eyes of the community back to Church.

The matching community for Rock Creek is Creighton which is located a few miles and has similar socio-economic characteristics. The community is said to be fairly united with two very active youth clubs. They have recently helped form a District Development Committee consisting of participants from the youth clubs and other individuals active in community activities. The church, however, is not involved in these activities and does not seem to play an active role in the development of the village. Focus group discussions explained that while the "Community is minimally involved," "those that attend meetings are mostly young people because they have time on their hands." Some also felt that the "Community not very united, politics divide the community during elections." Others believed that despite strong political divisions, the village was relatively harmonious.

Some of this lack of collective action capacity has affected the community's ability to apply for JSIF funds. We were told that the "community did not apply for JSIF because there was no consensus on which project was a priority...." On the other hand community members have worked together on a road construction project and are presently providing voluntary labor excavating land from the hillside to build a play field.

Perhaps the most important distinguishing factor between Rock Creek and Creighton is that Creighton does not have a single important problem, like the school destroyed by fire, that is able to unite the community in an effort to deal with it. In Rock Creek the lack of a school motivated young people in the Sports Club to work hard to galvanize the community to organize itself and apply for JSIF funds. Creighton on the hand, suffers from several problems, the lack of adequate water, poor roads, the lack of a school building, and there is no clear sense of which of these is a priority. The multiple problems serve to divide the community rather than unite it.

\section{Summarizing the Qualitative Evidence:}

In interpreting the qualitative evidence it helps to reiterate the point that the information is based upon interviews with a few key informants in each community, and focus group discussions. Since the focus groups were not selected on the basis of a probability sample, it is possible that the views they present may not be representative. The qualitative evidence therefore should be evaluated in conjunction with the quantitative evidence, which is based on a random sample, to get a comprehensive sense of the impact of the project on the community. 
The qualitative data indicate that the Social Fund had, overall, a positive impact on each of the five communities in our sample. JSIF generally follows a procedure where careful social analysis precedes the design of a project. While the community is generally well informed about the project, participation for the sake of participation does not seem to be the highest priority. In the case of Arnett Gardens and Port Royal, for instance, levels of participation were very low. Community members were given the opportunity to attend meetings where they were given information about the project, but this does not mean that they had a voice in the choice of the project. The focus group interviews seem to indicate that many would have preferred a different type of project - usually one that generates private goods like more jobs.

However, Jamaica's political culture, and the many divisions that exist within its communities may make the participatory process difficult to implement in a manner that is truly inclusive. Typically a leader within the community receives support from one faction within the community and not with another. This creates a situation where the project tends to incorporate the interests of one sub-group of the population while ignoring the others. This in turn has the potential to both generate a project that benefits many members of the community, but simultaneously reinforce divisions within it, as we saw in Port Royal and Virginia. The question that should be asked is whether participation within a heterogeneous, divided, community is possible or even desirable. A truly participatory process was perhaps impossible in a community such as Arnett Gardens. Participation in this case was substituted by careful social analysis that helped inform the development of a project that, at least for a while, had a positive effect on the community. This suggests that what really seems to matter is a deep knowledge of the social, political and economic forces underlying a community - whether this comes from "participation" or social analysis. Thoughtful investigation - whether done by "listening" to the community or by simply listening to good social scientists can result in effective project design.

Divided communities also create the pre-conditions for capture. However, despite the lack of full participation, what we see in each of these cases is not capture but what one World Bank official ${ }^{5}$ calls "benevolent capture." This describes a situation where influential individuals within a community push through a project and dominate its progress, but do it with communitarian motives which have the effect of having a generally positive impact. The point of Community Driven Development is to involve the community in a development intervention so to create a better match between the community's needs and the project it obtains. How this is achieved is perhaps of secondary importance. It helps to have a wide menu from which to choose from which, JSIF, to its, credit, seems to allow for. The Tony Spaulding stadium, the Virginia basic school, and the New Valley road project are cases in point. Participation, as in the case of Virginia and New Valley by having communities send applications which are then vetted and

\footnotetext{
${ }^{5}$ Aniruddha Dasgupta who manages urban CDD projects in Indonesia.
} 
checked - is one way to achieve this goal. But, as the Tony Spaulding stadium demonstrates, this may not always make sense in communities that are more difficult to work in because of severe social disruption.

To summarize, we have learned from the qualitative analysis that the CDD process is often dominated by a sub-set of the population mobilized by a local leader who may or may not be a politician. The process of project selection is not generally participatory but is driven by the opinions of this small motivated group. Once construction commences, however, we see that this group is often able to motivate a larger group in the community to participate by making contributions to the project. Once the facility has been completed, it is generally positively viewed and seen as something that belongs to the community that was constructed with the community's active support and participation. Given that the process of project selection is dominated by a small group, it would be interesting to see if participation was selective and exclusionary. Note that this general pattern does not apply to Arnett Gardens, which is essentially an "informed" top-down project where carefully social analysis preceded the design and implementation of the facility. Arnett Gardens also reminds us that the positive social externalities that arise from a community based intervention - however well designed - may be difficult to sustain in the long term in communities that are beset by deep divisions. We will now turn to the quantitative data explore these issues greater detail. We will examine the determinants of participation, and see the extent to which community interactions and the capacity for collective action have been affected by the social fund. We will therefore understand the extent to which our qualitative findings can be generalized to the population. We will also attempt to examine the causal impact of the social fund process on the community's capacity for collective action and participation.

\section{Quantitative Data and Methodology}

Each of the five pairs of communities described above have been matched on the basis of observable characteristics such as the availability of public services and levels of poverty, but the field visits also helped match them on "unobservables" such as their geography, political culture and social structure. Within each community, fifty households were selected at random to be administered the questionnaire. Within each household an attempt was made to interview two adults: the head of the household and one another randomly chosen member of the opposite sex to the household head. In practice, Jamaica's family structure, which tends to be have a large proportion of single parent households, made it difficult to locate the second adult in many households. Therefore we have a sample of about 500 households with 684 individuals, spread evenly between social fund and non social fund communities.

The questionnaires that were administered to these households covered issues that ranged from socio-economic characteristics, experience with community based activities and participation in projects 
prior to the introduction of the social fund, sources of information prior, networks, perceptions of problems in the community, information and knowledge about the social fund, level of participation in community and social activities, and a series of questions that asked respondents to evaluate changes from five years ago to the present on a series of outcome variables (the social funds started operating in these communities in 1997). The questionnaires for the social fund and non-social fund communities were similar, the only difference being that social fund communities were asked an additional set of questions that were unique to the social fund process. The analysis will focus on two sets of dependent variables - one set will analyze targeting and participation focussing on data from the social fund communities, the second set will compare social fund to non-social fund communities in order to tease out the impact of the social fund on changes in various indicators of the capacity for collective action.

Our data suffers from two important problems, common to many impact evaluations, that affect our ability to determine the causal impact of the social fund program:

A) Since the access to the social fund was not randomly assigned we are not able to observe what would have happened to a community had it not received assistance from JSIF.

B) We do not have direct observations on the communities prior to the introduction of the social fund.

To elaborate on these concerns and to outline how we attempt to find solutions to them we will briefly sketch the elements of the impact evaluation problem us ing Ravallion's (2000) notation:

Let $I_{i}$ be the impact of the Social Fund on individual i. Then, $I_{i}=Y_{1 i}-Y_{0 i} \mid P_{i}=1$. Where $Y_{1 i}$ is the outcome of interest for individual $\mathrm{i}$ when that individual belongs to a community that received treatment 1 . $\mathrm{Y}_{0 \mathrm{i}}$ is the outcome when the same individual belongs to a community that did not receive the treatment. This is conditional on $\mathrm{P}_{\mathrm{i}}=1$, i.e. the probability that the individual belongs to a community that received the treatment is 1 . In other words, the true impact of the social fund is measured by looking at the difference between the outcome with the social fund intervention and the outcome without the social fund intervention, for the same individual in the same community. Obviously, till cloning technologies become more cost effective, this is never observable. That is, we can never observe $Y_{0 i}$ when $P_{i}=1$; the outcome of what would have happened had the treatment not been received in a community that received the treatment. This is crux of the problem with program evaluation.

The ideal solution to this problem is to do a random assignment which, on average, will give us the correct answer. If we define the expected value of the impact as:

$$
\mathrm{I}=\mathrm{E}\left(\mathrm{Y}_{1 \mathrm{i}}-\mathrm{Y}_{0 \mathrm{i}} \mid \mathrm{P}_{\mathrm{i}}=1\right)=\mathrm{E}\left(\mathrm{Y}_{1 \mathrm{i}} \mid \mathrm{P}_{\mathrm{i}}=1\right)-\mathrm{E}\left(\mathrm{Y}_{0 \mathrm{i}} \mid \mathrm{P}_{\mathrm{i}}=1\right) \text {. }
$$

Then, if the social fund was assigned randomly to a group of communities which constituted the treatment group, while the rest were left as controls, so long as the sample was randomly drawn we can assume $\mathrm{E}\left(\mathrm{Y}_{0 \mathrm{i}} \mid \mathrm{P}_{\mathrm{i}}=1\right)=\mathrm{E}\left(\mathrm{Y}_{0 \mathrm{i}} \mid \mathrm{P}_{\mathrm{i}}=0\right)$. The expected value of the outcome without a social fund in the treatment group would be the same as the expected value of the outcome without a social fund in the experimental 
group. We would then get an unbiased estimate of the average treatment effect. However, we know that Social Funds were not randomly assigned. In fact, JSIF explicitly states that they have a pro-poor bias. One way around this is to select matched pairs of communities which are very similar so that we can assume $\mathrm{E}\left(\mathrm{Y}_{0 \mathrm{i}} \mid \mathrm{P}_{\mathrm{i}}=1\right)=\mathrm{E}\left(\mathrm{Y}_{0 \mathrm{i}} \mid \mathrm{P}_{\mathrm{i}}=0\right)$ with some degree of comfort.

This, however, is imperfect. For example, looking at the qualitative work we see that while Port Royal is similar to its matched community Rennock Lodge, Rennock Lodge does not share Port Royal's unique history and social structure. This problem has a solution if we assume that the differences between the matched pairs are time invariant. In other words, we can assume that the kinds of things that make Rennock Lodge different from Port Royal do not change over time - a safe assumption since much of what makes them different is related to their uniqueness as communities which is unlikely to change rapidly over time. If the source of bias is time invariant, and if we have observations on these communities over time preferably before and after the introduction of the social fund in the experimental community, we can take the difference between two time periods in each community to eliminate time-invariant sources of bias. We can then take another difference across the experimental and control matched pairs to get a better estimate of the causal impact of the social fund. This gives us the difference in difference estimate:

$$
\hat{I}=\mathrm{E}\left(Y_{1 \mathrm{it}}-Y_{1 i t-1} \mid P_{i}=1\right)-\mathrm{E}\left(Y_{0 i t}-Y_{0 i t-1} \mid P_{i}=0\right)=\mathrm{E}\left(\Delta Y_{i} \mid P_{i}=1\right)-\mathrm{E}\left(\Delta Y_{i} \mid P_{i}=0\right)
$$

In our data we do not have direct observations of these communities before the introduction of JSIF but we asked respondents a series of retrospective questions about life five years before March 2000, which takes us to a period the year before JSIF was introduced to get a sense of initial conditions. We also asked them to directly assess how their lives have changed for a series of outcome variables from five years ago to the present and therefore provide a direct measure of $\Delta Y_{i}$ in both pairs of communities. This is an imperfect solution since memories are sometimes poor, but it in the absence of panel data it provides one way of deriving estimates of change.

This method, however, does not allow to assess how different individuals are differentially affected by the change. While it may be safe to assume that the differences in the two matched pairs of communities are time invariant, it may be more difficult to assume the same for individuals in those communities. We know that if unobservable characteristics change over time our difference in difference estimates will still be biased. Also, it may be interesting to examine how particular characteristics of individuals affect changes in outcomes, and how those characteristics may be affected by the social fund process. For instance we may interested in know if better educated individuals are more likely to participate in group meetings, and if the social fund process has a greater impact on better educated people.

In order to find a solution to the problem of bias due to time-variant unobserved heterogeneity and to get a better sense of how the program effects varied across individual we will employ propensity score 
matching methods. The idea behind the propensity score (Rubin 1973, Rosenbaum and Rubin 1983) is to create an index that summarizes the exogenous observable attributes of an individual. When this index is generated for the individuals in both the experimental and control groups, individuals in the experimental group can be paired with their statistical clones in the control group. If the observational and control samples are very different the propensity score will also identify individuals who have no corresponding match - that this they will lie outside the common support of the propensity score in the experimental and control samples. These individuals outside the common support are dropped to reduce bias in the estimate of the impact. To summarize we will calculate a propensity score on the basis of the following equation:

$$
\text { (1) } P_{i}=f\left(\mathbf{H}_{i}, \mathbf{X}_{i}, C_{i}\right)
$$

Where $\mathrm{P}_{\mathrm{i}}$ is the probability that the individual belongs to a social fund community. $\mathbf{H}$ is a vector of exogenous household characteristics, $\mathbf{X}$ is a vector of exogenous measures of behavior of the household related to participation prior to the introduction of the social fund, and $\mathrm{C}$ is a dummy variable for each pair of communities to control for regional differences. The vector $\mathbf{H}$ includes the sex of the respondent, his/her age and its square, whether the respondent is less than 25 years old, the household size, the number of earning members of the family, the highest le vel of education in the family, the number of children of school going age, whether the individual is Rastafarian, whether s/he is Protestant, whether s/he is a permanent resident of the community who has not migrated from elsewhere, whether the respondent is married or unemployed, and the household's economic status. Economic status is a principal component measure of a set of asset based variables using the method suggested by Filmer and Pritchett (2001), since the surveys did not ask questions on income or expenditure. The method for calculating the economic status variable is outlined in Appendix A.

In the vector $\mathbf{X}$ we include: the level of participation in community activities prior to JSIF, their primary method of socialization - whether they meet other members of the community primarily in community activities like PTA meetings, or whether they meet them through traditional activities such as weddings and funerals, the number of influential people they knew within the community prior to JSIF, and the number of influential people they knew outside the community prior to JSIF. $C$ includes dummy variables for each pair of communities analyzed in the qualitative section.

Equation (1) is estimated with a logistic regression, and the predicted probability $\hat{P}_{i}$ calculated from the estimated logit regression is the propensity score. As explained above, it can be viewed as a summary measure of all the exogenous variables in equation (1). As we will see below, because the pairs of communities have been matched closely during the sampling process the overlap between observations in the social fund and non-social fund samples is quite large which means that only a small percentage needs to 
be trimmed. However, dropping these extreme observations substantially reduces the bias in the estimated impact of the program (Heckman et.al., 1998).

We will analyze the impact of the intervention using nearest neighbor matching. Each observation in the social fund sample will be matched on the basis of the propensity score with its "nearest neighbor" in the non-social fund sample. Since the sample size is rather small, in practice, it is difficult to find an exact match and we therefore take the average of the five nearest neighbors from the control sample. The difference between the observation in the treatment sample and its matched (averaged) nearest neighbor in the control sample provides an estimate of $I_{i}$. The average of all the $I_{i}$ provides an estimate of $I$ the average treatment effect. Studies have shown that this average treatment effect provides results that are close to those obtained from a randomized trial (Dehejia and Wahba, 1998). We will also examine the impact of the impact on the social fund on intervening variables by calculating the nearest neighbor I for sub-groups of the population divided by education, age, economic status, and gender. We calculate bootstrapped standards errors for the nearest neighbor estimates to test whether the estimates of I are significantly different from zero. The nearest neighbor method provides the closest approximation to results from a random assignment and, unlike regression based methods, does not make any assumptions about the parametric relationship between the intervention and the outcome variables. In our view, it is therefore the preferred method to assess the impact of the social fund. Thus we employ two methods - difference in difference with matched samples of difference in difference with propensity score nearest neighbor matching to provide estimates of the impact of the social fund. This in combination with the qualitative evidence will provide an in-depth and comprehensive examination of the relationship between social funds and outcomes of interest.

The outcome variables we examine include: Have respondents heard of JSIF, Compared to five years ago whether it is easier now to work with groups and associations of people outside the immediate household, compared to five ago has there been a change in the level of trust in the community, compared to five years ago is it more easy to get the entire community to agree on a decision, five years ago were you more or less likely to be fined or penalized for not participating in community activities, compared to five years ago is the government more responsive to your needs, compared to five years ago is the local leadership more responsive to your needs, compared to five years ago are community decisions made more or less often by community leaders, and compared to five years ago are community decisions made more or less often by community meetings with a vote.

In addition to measuring the impact of the social fund, we are also interested in studying the determinants of participation within the social fund process. To examine this we focus on the entire social fund sample, without trimming. We will first begin by examining how close the project that each community obtained was to the expressed preferences of members. Each individual in the social fund sample was asked to rank order the three most important problems that they faced prior to the introduction 
of the project. The question was relatively open-ended allowing for a whole range or responses. These responses were then coded into categories that could be associated with interventions - such as education, roads, income generation, etc. We then focus on the problem that was listed as the most important by the respondents and rank orders the categories by the number of "votes" they receive ${ }^{6}$. The sample is then split into high and low levels of education, economic status, age and gender to see if the "votes" change for different types of individuals.

Finally, we run reduced form regressions on a variety of indicators of participation in the Social Fund process with the same set of exogenous variables as in equation (1). The indicators of participation we use include : Whether they had a meeting to decide about the project, whether they participated in any meetings during the course of the construction, and whether the JSIF project addressed the problem that was ranked as the most important by the respondent.

\section{Quantitative Results}

Table 1 provides summary statistics for the exogenous variables for the social fund and non-social fund communities. We see that the two samples are quite similar - none of the variables in the samples significantly different from each other - indicating that the quality of the match in the pairs of communities is good. The average age of a respondent is 45.3 (46.8 in the non social fund sample). The mean highest level of education in a household is 10.14 years (9.97 in the non social fund sample). Interestingly a little more than $50 \%$ of the sample consists of female headed households, which is consistent with demographic patterns in Jamaica. Prior to the inception of the social fund, participation in development projects was slightly higher in non-social fund communities, where the average household had participated in 1.87 projects prior to JSIF compared to 1.76 projects in JSIF communities. Non-JSIF communities had more frequent contact with their local leaders than JSIF communities. On average, JSIF communities are acquainted with 1.42 influential people within the community while this average is 1.06 for matched communities. Non-JSIF communities, on average, knew 1.35 influential people outside their community compared to 1.21 for JSIF communities ${ }^{7}$.

Table 8 reports the results from the propensity score regression - equation (1). Smaller households and migrants are more likely to belong to social fund communities. Individuals with higher levels of participation are less likely to belong to social fund communities, as are those who have participated in non-

\footnotetext{
${ }^{6}$ We also tried a "proportional voting" system by using all three responses and calculating a weighted vote with the highest weight given to the first problem, the second problem received $50 \%$ of the weight of the first problem and the third problem receiving $33 \%$ of the weight. This produced very similar results to the "majority vote" system and is therefore not reported for the sake of brevity.

${ }^{7}$ The variable "Influential people" is constructed by asking respondents whether they had frequent contact with a series of people such as the Mayor, pastor, extension worker, etc. It is, therefore, not self-defined.
} 
JSIF projects. Individuals well connected to leaders within the community are more likely to be in a social fund community, while those who have daily or weekly access to local leaders or connections to VIPs outside the community, are less likely to receive JSIF funds. Since the amount of community level variation is small, it difficult to read much into this regression but it does seem to suggest that individuals who have more experience with CDD projects are less likely to be in communities that receive social funds. To compare the JSIF and non-JSIF communities, Kernel densities for the propensity scores for both communities were plotted (Figure 1). Their curvature is similar, again indicating a good quality match. When the observations are trimmed to drop those outside the common support, we lose about 10 per cent of the sample in both the JSIF and non-JSIF samples and, as expected, differences between them substantially decrease (Table 1).

Before working with the trimmed sample, we will analyze the complete JSIF community sample to investigate how well targeted the projects were and to examine the determinants of participation in the JSIF process. One of the important potential benefits of community driven development is its demanddrivenness. The perception that by allowing a community to be in the driver's seat, there will be a good match between what the community needs and the project that it obtains. The qualitative work, however, indicated that because communities were divided - usually because of politics but also for other reasons projects were not really "participatory." They were driven by local leaders who, via a process of "benevolent capture," mobilized a few members of the community to obtain JSIF funding and, in the case of Arnett Gardens, the project was initiated entirely by outsiders.

To examine how close the project matched the expressed preferences of the community we construct a targeting indicator based on a question in the survey questionnaire that asked respondents to list the three most important problems they faced prior five years before the survey. While the responses were quite diverse, we categorized them to approximate a type of intervention. For instance, whether the problem was "the school does not have a roof," or that "the teachers in the school are not good," they were both categorized as "school" problems. These categorized responses were then tabulated to reflect a "majority vote" process, and a "weighted vote" process as described above.

Table 2 reports the results. The JSIF process resulted in a relatively imperfect match between the community's expressed needs and the project that was obtained - the category of needs that match with the project that was obtained are in bold. Two communities, Arnett Gardens and New Valley/Orange received their top priority project, as suggested by the qualitative evidence, while the other three did not.

Furthermore, communities that did not receive their most preferred project received projects that were ranked relatively low in their list of initial priorities. This is true whether one assumes that group decisions were made by majority vote which counts the most important problem, or whether the top three needs were counted in weighted proportional vote. On explanation for this could be that most important problems were 
often private goods - lack of credit and income generation for instance - which the social fund was unable to sponsor. But, even if we focus on public goods such as lack of water, health, poor roads, etc, we still see that the facility that was obtained is ranked very low. This is partly because of the menu that JSIF offers is usually restricted to health clinics, schools, water and road projects. However, even focussing on this narrow menu we still see that in three out five cases priorities that could have been addressed under the JSIF menu were ranked higher than the project that was obtained. Thus the evidence for community drivenness is rather poor. The preferences of the majority of the community did not seem to play a part in determining the project in the majority of the communities.

Moving to Table 5 we see a pattern as to whose votes count by examining if an individual's preferences matched with the project that was obtained. Looking at all three expressed needs we see that, in a cross-tab, people of higher education were more likely to have expressed a need that was associated with the facility that was obtained. This pattern is even clearer if we focus only on the most important need. In the estimates reported in Table 6 we see that better off families with lower family size who were permanent residents were more likely to have their priority needs satisfied. Networks also seem to matter as people with greater access to local leaders who were more sociable were also more likely to obtain their highest priority project.

However, even if a project does not address the priority needs of a majority in the community, it still may be a successful intervention if, via a process of benevolent capture, the community is ultimately mobilized and satisfied by the project. This is suggested by Table 7 which analyzes whether respondents said that they would have ultimately preferred another project. The table shows that 82 per cent would not have preferred another project. The regression results here do not show a significant relationship with almost all the variables indicating that there is no clear socio-economic group that was more satisfied with the project. Networks, and proximity to community leaders also does not seem to matter. Contrasting Table 7 with the targeting tables, one gets the sense that while the projects did not meet the ex-ante expressed preferences of the community, ultimately most people were satisfied with the choice. Therefore, the CDD process suggests a process of information transmission and persuasion by a small group of individuals who are associated with the leadership. While ex-ante targeting is poor, and the participation process relatively exclusionary, most in the community seem satisfied with the end result.

Table 3 provides estimates of a regression of whether the community had a meeting to decide about the project. Since four of the communities had at least one meeting about the project, this is as much an indicator of an individual's information about the role of JSIF in the community as it is an indicator of participation. Note that only $53 \%$ of respondents gave a positive response to the question. We see that age has a quadratic effect on this with a negative sign at the mean. Thus younger people are better informed on average but the very young are as ill informed as the old. As expected, individuals in Arnett Gardens are the 
least likely to have had a meeting. Families with more earners, more experience with participation, and with better connections to leaders within the community on the other hand are more likely to have heard about the project. This suggests that there is a small core group of people in the community who tend to participate in development activities, who also may be well connected with the local leadership.

Having examined the extent of knowledge about JSIF meetings and the congruence between people's preferences and the project that they obtained, we turn to studying the determinants of participation in the JSIF decision making process. First we will look at who participated in Social Fund meetings. Table 4 provides some insights into this (with 27 per cent of the sample reporting that they had participated in at least one meeting) Here we see that individual socio-economic characteristics do not seem to matter as much as experience with participation. Non-Migrants, people who participated in projects prior to JSIF, and those who are well connected with leaders within and outside the community are more likely to have attended a meeting. Note, once again that Arnett Gardens has the lowest level of participation. This once again suggests that active participants tend to be a small groups of motivated people who tend to be active in community politics. But this variable, in conjunction with the targeting results, suggests that while the poor participate they do not necessarily obtain their priority projects. This raises the possibility that the non-poor may benefit more from participation than the poor.

The picture that emerges about targeting and participation in the JSIF process is, therefore, quite clear. Participation seems to have been restricted to a small group of active individuals who were close to the community leaders and were highly motivated. The entire process is best characterized as benevolent capture. It was not a broad based community driven process but pushed and activated by a few local leaders who nevertheless seemed to be doing it for reasons that benefited the community. Their private reasons for doing so are unclear, but obtaining the JSIF project clearly enhanced their stature within the community. In Arnett Gardens, we have a special case where participation was practically non-existent and the entire process was driven by outsiders - in that sense it could be called informed top down. Arnett Gardens was also the best targeted of the projects in that it attempted to address the most important concern of the vast majority of community members. New Valley/Orange, as shown in the qualitative section, was also well targeted in that the community received a project that addressed its most pressing need - a good road. The other projects in our sample, on the other hand, were extremely poorly targeted and would have performed abysmally in a vote. Moreover, targeting also seems to have not been pro-poor with better educated and better networked individuals much more likely to receive their preferred project. One reason for the education effect, however, was that three of the five projects in our sample are school renovations which are likely to have been favored by more educated members of the community. However, ex-ante only 20 per cent of respondents would have preferred another project. Therefore, while the CDD process may have been 
exclusionary with poor ex-ante targeting, once the proje ct had been completed and was functioning most in the community seemed satisfied by the choice.

We now shift focus to examining the impact of the social fund project on the community. We will use data from both the JSIF and non-JSIF communities trimming observations outside the common support of the propensity score from both samples. Each outcome variable that we look at will be examined in two different ways - cross-tabs (which provide a difference in difference estimator with matched samples when the outcome variable is a retrospective question on changes over time) and difference in difference with propensity-score nearest neighbor matching. We first begin examining the set of outcome variables expressed in terms of changes from five years ago, prior to the introduction of JSIF. Table 9 examines if respondents find it more easy or more difficult to participate in groups or associations of people outside their immediate households. The cross-tabs show a clear JSIF impact, as do the nearest neighbor estimates. The JSIF process clearly seems to make it easier for people to work with other members of the community. However, the nearest neighbor estimates show a significant wealth effect suggesting that JSIF may have created more collective action capacity among the rich than among the poor which against suggests an element of "elite capture." A Social Fund project within the community is more likely to enhance the capacity of the relatively well off to engage in collective action.

Table 10 reports results from an analysis of changes in levels of trust. Trust is not an easy concept to define or measure. The question did not attempt any explanation of the word but simply asked if "levels of trust and community cooperation" changed, before and after the JSIF, between people from different backgrounds in the community. This is relatively vague, and the results should be interpreted with caution and examined in conjunction with the other outcome variables. However, since English is Jamaica's official language and is widely spoken and understood, the English word "trust" is likely to have been understood in similar ways by all the respondents in the five pairs of communities. The cross-tab results tell us that trust has slightly increased in the JSIF community, a finding that is confirmed by the propensity score results. The nearest neighbor estimates also present evidence to suggest that the increases in trust may have been significantly higher for those who identified themselves as Protestant emphasizing the important role of the church in Jamaica's communities.

Table 11 examines a related question - compared to five years ago is it now more difficult or easy to get the entire community to agree on a decision. The difference in difference cross-tabs show a slightly positive JSIF effect, but the nearest-neighbor estimates show a small but insignificant effect. The nearest neighbor estimates, moreover, also suggest that any improvements in the ability to reach collective decisions were more likely to have been realized by better networked and employed individuals. Thus, we can infer that while JSIF did not have much of an impact on improving the ability of individuals to reach collective 
agreements, these changes were more likely to have been realized by economically more stable and better networked individuals.

Examining these collective action variables as a group, it does suggest that the JSIF process has built the community's capacity for collective action by enabling the community to work together as a group across people of different backgrounds, and by increasing trust. How sustainable this will be is less clear. The projects are new and the community's experience with collective action in the construction and management process is still fresh in their minds. But, we have already seen warning signs in Rock Creek and Arnett Gardens that this improvement in collective action may not be sustainable. This lack of sustainability has a historical precedent in Jamaica's history with the Jamaica Welfare Society, where interest and support in the cooperative movement withered away as fashions changed and prime movers passed on. The vestiges of the Society either died or became entrenched as part of the elite - as in the case of the Port Royal Brotherhood. Therefore a question still remains whether the burst in enthusiasm for collective action generated by the social fund will prove resilient over the long term. It should be kept in minded that any new innovation within a community is likely to generate some enthusiasm and "a spirit of ecumenism" to quote the New Valley focus group. Furthermore, if the capacity for collective action that is generated by social fund process is not kept aflame with opportunities and funding for further development initiatives, it is likely to turn very quickly to disillusionment. JSIF, like most Social Funds, is financially constrained and potentially unlikely to have the resources to permit a community to apply for a second project. Unless this is rectified, the CDD process may have the potential to result in a level of disillusionment that is perhaps even greater than in regular top-down projects because of the level of hope that CDD engineers within activist groups in a community.

We now turn to perceptions of how the process of decision making within the community has changed, and the effectiveness of leadership and governance. Table 12 asks if respondents believe that community leaders are more responsive to their needs. Since the qualitative data revealed that the CDD process was often driven by local leaders - both formal and informal - this question checks to see if their efforts have resulted in a perception of greater responsiveness. The data show no JSIF effect either in the cross-tabs or the nearest neighbor estimates. The nearest neighbor estimates show, however, that JSIF effect is stronger for younger individuals, those who are married and those who are better networked outside the community. Therefore, while JSIF does not seem to have increased overall perceptions of community leader effectiveness, it was more likely to have done so with younger, married and better networked individuals.

Table 13 provides an interesting contrast - examining whether community decisions are now more likely to be made by community leaders. Here we see a positive JSIF effect both in the cross-tabs and the propensity score nearest neighbor estimates. The nearest neighbor results also reveal that less educated and 
older individuals are more likely to report that decisions are made more by community leaders. Also notice that non-JSIF communities have also seen an increase in the role of the community leader, suggesting that there is a decentralization process at work in Jamaica that seems to be affecting communities regardless of their contact with JSIF. Tables 12 and 13 together indicate that the power of community leaders has increased in all communities, but particularly so in JSIF communities. However, this increased power is not perceived by the community to have increased the community leader's responsiveness and effectiveness. They do not seem to be getting credit for JSIF initiatives despite the fact that they are so strongly driven by community leaders.

Table 14 focuses on changes in the role of the community in making decisions - on issues of "voice" by reporting results on changes in decisions made by community vote. The variable does not show a JSIF impact - there is no discernable difference between JSIF and non-JSIF communities on community decisions with vote. However, perceptions of improvements in democratic decision making are more likely to have been reported by younger individuals. Respondents with access to important people within the community are also more likely to perceive an improvement, again indicating that better networked people are more likely to have been consulted about community decisions in this process. Note again, that both JSIF and non-JSIF show an increase in democratic decision making over the period suggesting that community driven mechanisms may be making inroads in Jamaica outside the JSIF initiative as well as within it.

\section{Conclusion and Policy Implications}

The overall sense that we get of the impact of JSIF on the capacity for collective action is consistent across both the qualitative and quantitative data. JSIF does seem to have had a social impact - trust has increased, and people from JSIF communities are more likely now to be able to work with strangers in making community-based decisions. However, the JSIF process does not seem to have been very democratic with community leaders dominating decision- making. The data suggest that JSIF may have strengthened the hand of community leaders. When leaders are benevolent this could be a good thing, but if they are corrupt then this could result in bad outcomes. In these communities - overall - they seem to have been leaders who had the best interests of the community at heart. While it seems that respondents are for the most part happy with the project and with JSIF, and that JSIF has built good feelings within the community, it is not clear that the JSIF process has democratized decision making, any more than other processes present in Jamaica. It also seems to have improved the capacity for collective action, but whether these improvements will be sustained over the long run is unclear. 
Community Driven Development does not seem to have succeeded in doing what is touted to be one of its main advantages - to improve the match between what the community needs and the projects that it obtains. We see that perhaps because the CDD process is dominated by small group of motivated individuals mobilized by a leader, targeting is very poor with three of the five communities not obtaining the project that would have been preferred by a majority. Ironically, one of the two cases where the match between community preferences and the project was well done was essentially a top-down project - the stadium in Arnett Gardens. However, this could be characterized as "informed top-down." Extensive social analysis led to a project designed to address the most compelling need of the community - its plague of violence. Since the community was so fragmented and conflict ridden, participation would have been very difficult to achieve. Thus project implementation was entirely top-down with JSIF and an local NGO hiring the contractor, supervising the construction, with the community not making any contributions.

Consultations with the community were the result of PPA and focus group discussions conducted by a team of anthropologists - no one was mobilized or had to attend any meetings. This suggests that good social analysis could substitute for a community driven participatory process, particularly in complex, heterogeneous communities. The other alternative could be to simply subject a project menu to a secret ballot within the community or to conduct a needs assessment. However, by the end of the JSIF process, people seem to be satisfied with the choice of project, a contrary finding which suggests that CDD is primarily a process of persuasion and learning.

One potentially worrying finding indicated by the quantitative data is that better off, better networked individuals seem to dominate the participation process and receive their preferred projects. Moreover, they are also more likely to develop collective action skills. This suggests that the CDD process in Jamaica may compound existing inequities and even perpetuate them by enhancing the ability of the better educated and better off to work more effectively as a group. The fact that community leaders are not perceived to be more effective but are perceived to have a greater say in decisions as a result of the JSIF process, particularly by less educated individuals, also provides some evidence of a bias against the poor. This may not be intentional, but is the result of a process that requires a high level of literacy and political awareness to obtain a successful outcome. One open question that remains is whether the collective action skills built within a section of the community results in more sustainable projects. Since none of the facilities are more than three years old, and it is difficult to find a comparable counterfactual for them, it is difficult to tell if facilities assisted by the social fund are better run and better managed.

Community Driven Development is clearly no panacea. In societies that are sharply divided, it is difficult to achieve consensus on projects that meet the priority needs of the majority of the community. This may increase the possibility of "capture." A few educated, motivated, individuals led by effective leaders may be able to obtain funds for project that are relatively more beneficial for them. Yet, this capture 
may be "benevolent" in the sense that such projects may serve to benefit the entire community in the long run with the vast majority of individuals in the community ultimately expressing satisfaction with it. Does this compare well with a traditional top-down project? It is difficult to say with these data, but participation does seem to create a greater sense of accomplishment and ownership within the community. On the other hand, targeting could be improved by the simple act of instituting a needs assessment or having the community vote by secret ballot for a project. But again, if a project was better targeted, say by a secret ballot, would we see a group of motivated people work hard to keep it going with a spirit of "ecumenism?" In other words, if CDD has the potential to provide a community with a school to which everyone has access, and which is constructed and managed by a group of educated and motivated individuals this is not such a bad thing. On the other hand, the argument that CDD "empowers the poor" is clearly not indicated by these data. There is more evidence in support of the belief that it improves the capacity for collective action, but these data are unable to provide unambiguous answers to whether this results in more sustainable projects. To answer the sustainability we would require data that has a clear counterfactual - evidence on similar facilities provided by a CDD and a non-CDD process, and that are tracked over an extended period to see how the relationship between participation and sustainability evolves over time. Such data are, at the moment, unavailable. 


\section{APPENDIX A}

\section{Principal Components - Economic Status}

Economic status or household "wealth" can be approximated by an index of assets. Four approaches can be used to create an index of economic status. First, assume equal weights for all the assets. Second, impose weights for each asset, like price of the assets. Third, include the assets directly in the regression. The first two procedures are arbitrary because they assume weight for each asset. The third procedure does not allow us to differentiate from the coefficients the impact of wealth on the final outcome (Filmer and Pritchett, 2000). The fourth approach is to use principal components to determine an index of wealth. Principalcomponents is a procedure for extracting common information from a number of variables by calculating the orthogonal linear combinations of the variables which describes better the common information. The assumption is that common variation in the variables included in the principal components procedure is caused by wealth.

The asset index that approximates economic status for household $i$ is defined as $\mathrm{W}_{\mathrm{i}}=\mathrm{f}_{1} *\left(\mathrm{w}_{\mathrm{i} 1}-\mathrm{w}_{1}\right) / \sigma_{1}+\ldots+\mathrm{f}_{\mathrm{n}} *\left(\mathrm{w}_{\mathrm{in}}-\mathrm{w}_{\mathrm{n}}\right) / \sigma_{\mathrm{n}}$, where $\mathrm{f}_{1}$ is the scoring factor, $\mathrm{w}_{\mathrm{i} 1}$ is the $i$ th household value for the first asset, $\mathrm{w}_{1}$ is the mean for the first asset and $\sigma_{1}$ is the standard deviation of the first asset.

For Jamaica, two sets of variables were considered. The first set, defines characteristics of the house such as roof of concrete or tile and connection to electricity and water. The second set of variables represents assets owned by the household.

Table 1. Scoring Factors for Jamaica

\begin{tabular}{|l|r|}
\hline & $\begin{array}{l}\text { Scoring } \\
\text { Factor }\end{array}$ \\
\hline Tile Roof & 0.1096 \\
\hline Electricity connection & 0.3610 \\
\hline Flush Toilet & 0.3623 \\
\hline Water Connection & 0.3722 \\
\hline Own a car & 0.1164 \\
\hline Own other home & 0.0550 \\
\hline Own a motorcycle & 0.0405 \\
\hline Own a bicycle & 0.1599 \\
\hline Own a fan & 0.3589 \\
\hline Own a radio & 0.2259 \\
\hline Own gold or silver jewelry & 0.2763 \\
\hline Own television & 0.3498 \\
\hline Own refrigerator & 0.3804 \\
\hline Own major furniture & 0.1444 \\
\hline
\end{tabular}




\section{$\underline{\text { References }}$}

Abraham, Anita and Jean-Philippe Platteau, "The Dilemma of Participation with Endogenous Community Imperfections," mimeo, Department of Economics and CRED, University of Namur, 2001

Chase, Robert S. and Lynne Sherburne -Benz, "Household Effects of Community Education and Health Initiatives : Evaluating the Impact of the Zambia Social Fund," mimeo, January 2001

Conning, Jonathan and Michael Kevane, "Community Based Targeting Mechanisms for Social Safety Nets," mimeo, December 2000

Cornia, Giovanni Andrea, "Social Funds in Stabilization and Adjustment Programmes: A Critique," Development and Change, Volume 32, Pp: 1-32, 2001

Dehejia, Rajiv H. and Sadek Wahba, "Propensity Score Matching Methods for Non-Experimental Causal Studies," NBER Working Paper No. W6829, December 1998

Duncan, Grace Imani, “Arrested Development: Building Peace in the Inner-City of Kingston, Jamaica, mimeo, Harvard University, March 2001

Duncan, Grace Imani and Michael Woolcock, "Arrested Development: The Political Origins of Common Violence in Jamaica," mimeo, 2001

Filmer, Deon and Lant Pritchett, "Estimating Wealth Effects Without Expenditure Data - Or Tears: An Application to Educational Enrollment in States of India," Demography, Vol. 38 \#1, Pp: 115-132, 2000

Galasso, Emanuela and Martin Ravallion, "Decentralized Targeting of an Anti-Poverty Program," mimeo, Development Research Group, The World Bank, February 2001

Girvan, D.T.M, Working Together for Development: D.T.M. Girvan on Cooperatives and Community Development 1939-1968, (Compiled and Edited by Norman Girvan), Institute of Jamaica Publications Limited, 1993

Heckman, James, Hidehiko Ichimura, Jeffrey Smith and Petra Todd, "Characterizing Selection Bias Using Experimental Data,” NBER Working Paper Series \#6699, August 1998

Jamaica Constabulary Force, “Citizens Charter,” January 2001

Keith, Nelson W. and Novella Z. Keith, The Social Origins of Democratic Socialism in Jamaica, Temple University Press, Philadelphia, 1992

Khwaja, Asim Ijaz, "Can Good Projects Succeed in Bad Communities: Collective Action in the Himalayas," mimeo, Harvard University, March 2001

Moser, Caroline and Jeremy Holland, Urban Poverty and Violence in Jamaica, World Bank Latin American and Caribbean Studies, The World Bank, 1997

Narayan, Deepa and Katrinka Ebbe, "Design of Social Funds: Participation, Demand Orientation and Local Organizational Capacity,” World Bank Discussion Paper \# 375, The World Bank, December 1997 
Newman, John, Menno Pradhan, Laura Rawlings, Geert Ridder, Ramiro Coa and Jose Luis Evia, “An Impact Evaluation of Education, Health and Water Supply Investments of the Bolivian Social Investment Fund," mimeo, The World Bank, December 2000

Owen, Daniel and Julie Van Domelen, "Getting an Earful: A Review of Beneficiary Assessments of Social Funds," Social Protection Discussion Paper \#9816, The World Bank, December 1998

Rao, Vijayendra, "Poverty and Public Celebrations in Rural India," Annals of the American Academy of Political and Social Science, Volume 573, Pp: 85-104, January 2001

Ravallion, Martin, "The Mystery of the Vanishing Benefits: Ms. Speedy Analyst's Introduction to Evaluation," Policy Research Working Paper \#2153, The World Bank Development Research Group, July 1999

Rosenbaum, Paul. R. and Donald B. Rubin, "The Central Role of the Propensity Score in Observational Studies for Causal Effects," Biometrika, Vol. 70, Pp: 41-55, 1983

Rubin, Donald B., "The Use of Matched Sampling and Regression Adjustment to Remove Bias in Observational Studies," Biometrics, Vol. 29, \# 1, Pp: 185-203, 1973

Tendler, Judith with Rodrigo Serrano, "The Rise of Social Funds: What are they a Model Of?," mimeo, Department of Urban Studies and Planning, Massachusetts Institute of Technology, January 1999

Tendler, Judith, "Why are Social Funds So Popular?," Chapter 14, Local Dynamics in an Era of Globalization : 21st Century Catalysts for Development, edited by Shahid Yusuf, Weiping Wu and Simon Evenett, World Bank and Oxford University Press, 2000

Van Domelen, Juile "Do Social Funds Reach the Poor? A Review of Targeting Performance in Six Countries," Social Funds 2000 Study, Seminar Presentation, March 2001

Woolcock, Michael and Deepa Narayan, "Social Capital: Implications for Development Theory, Research and Policy," World Bank Research Observer, Volume 15, \#2, Pp: 225-249, 2000

World Bank, "Nicaragua: Ex-Post Impact Evaluation of the Emergency Social Investment Fund (FISE)," Human Development Sector Management Unit, Latin America and Caribbean Region, The World Bank, December 2000 


\section{Figure 1}

\section{Major Crimes Committed in the Kingston Western Division 1990-2000}

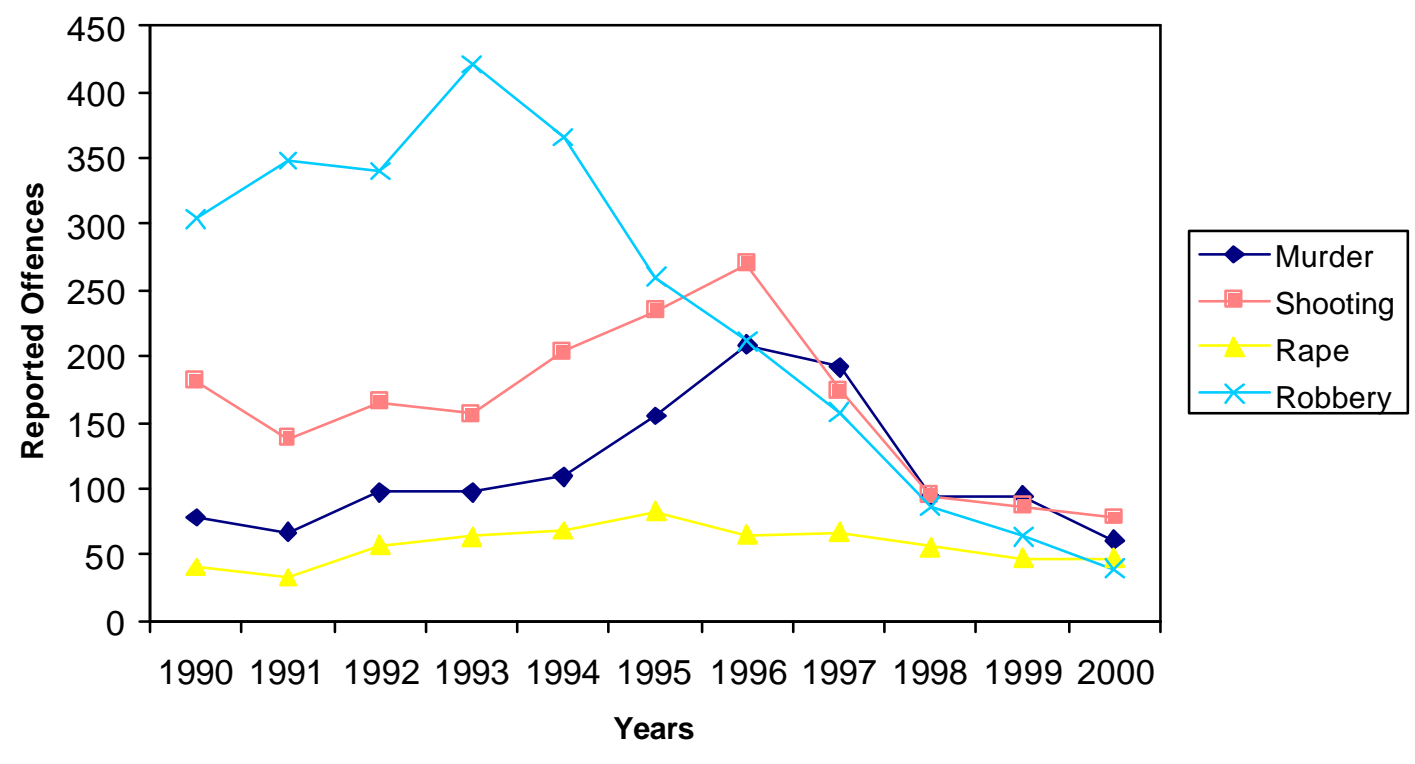

From Duncan (2001) based upon data from the Jamaica Constabulary Force, "Citizens Charter," January 2001

Figure 2

Total Murders in Jamaica less Kingston Western versus Total Murders in Kingston Western Division 1990-2000

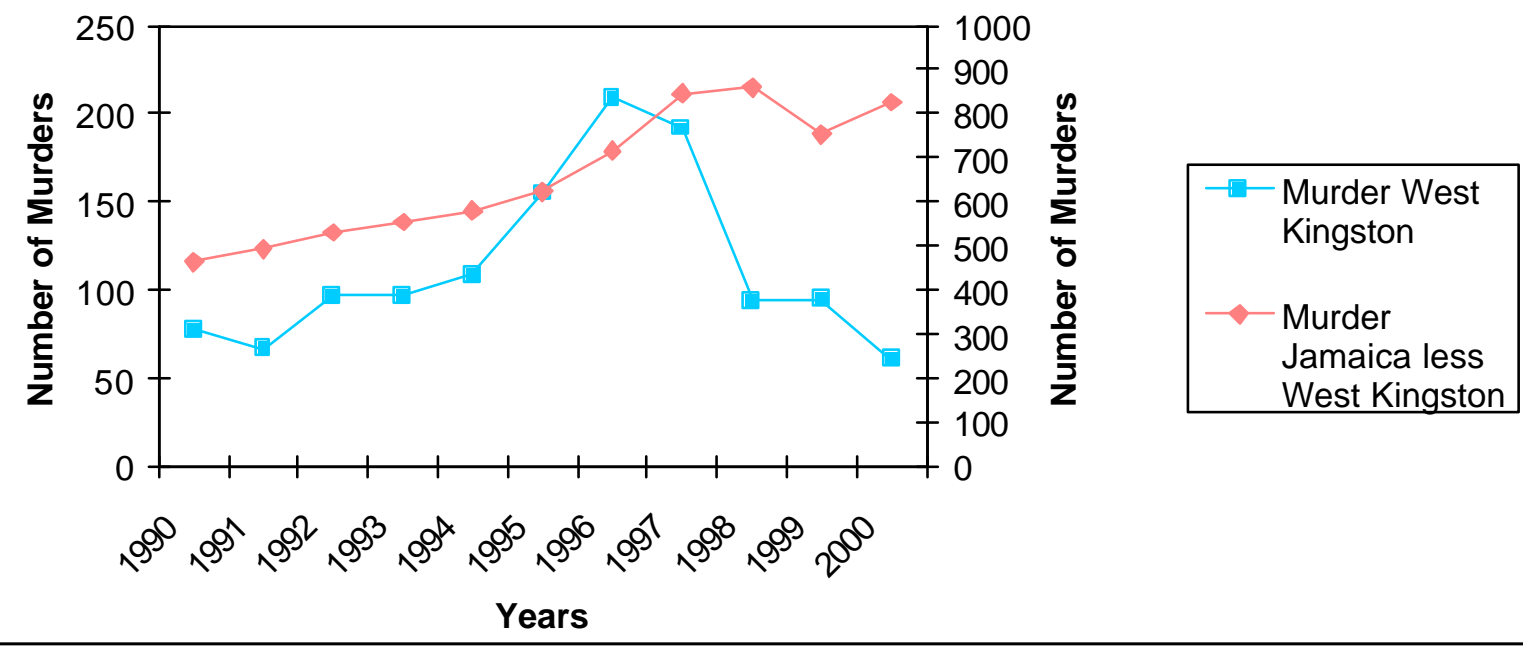

From Duncan (2001) based upon data from the Jamaica Constabulary Force, "Citizens Charter," January 2001 
Figure 1

Propensity Score Before Trimming

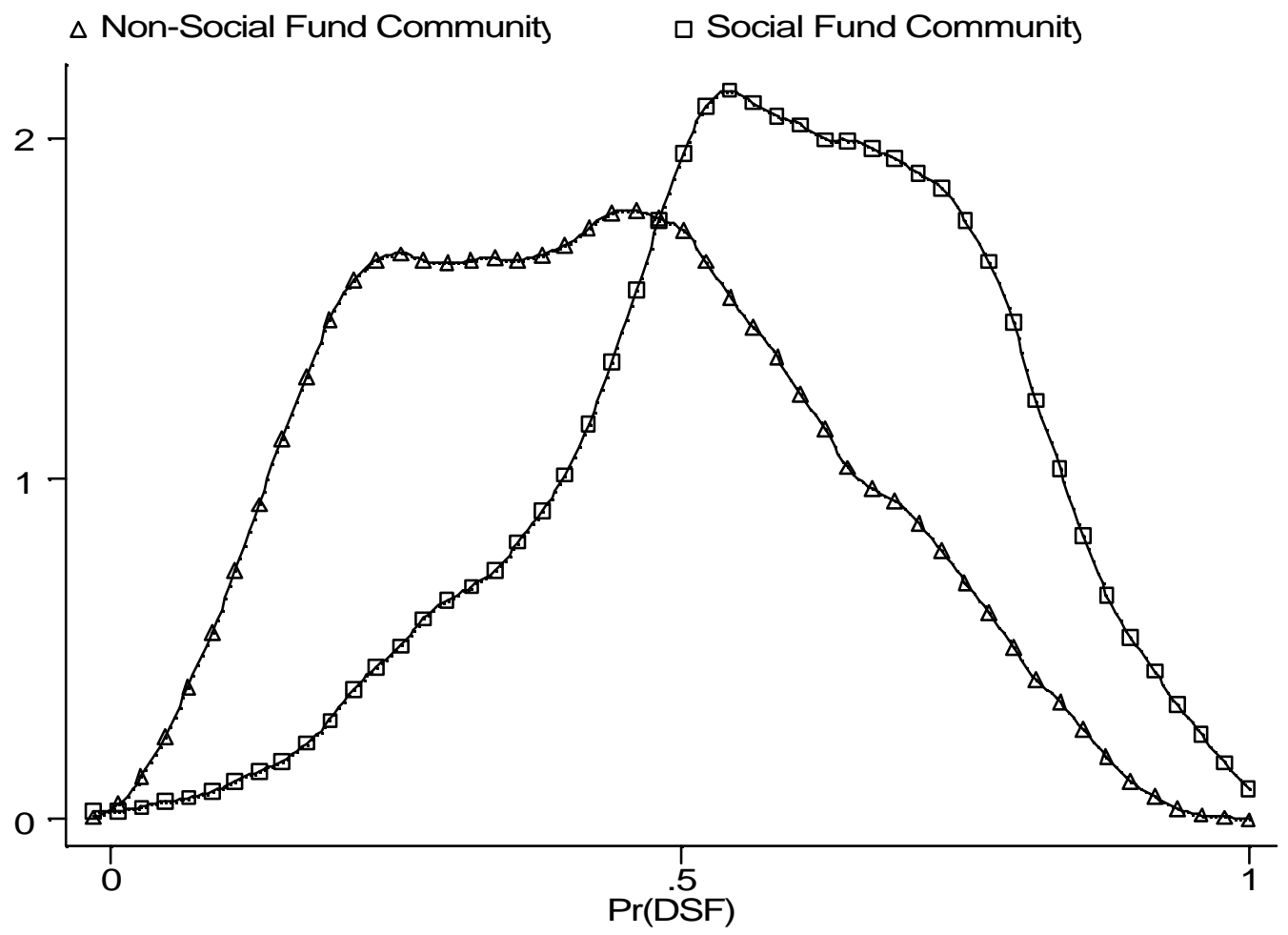


Table 1

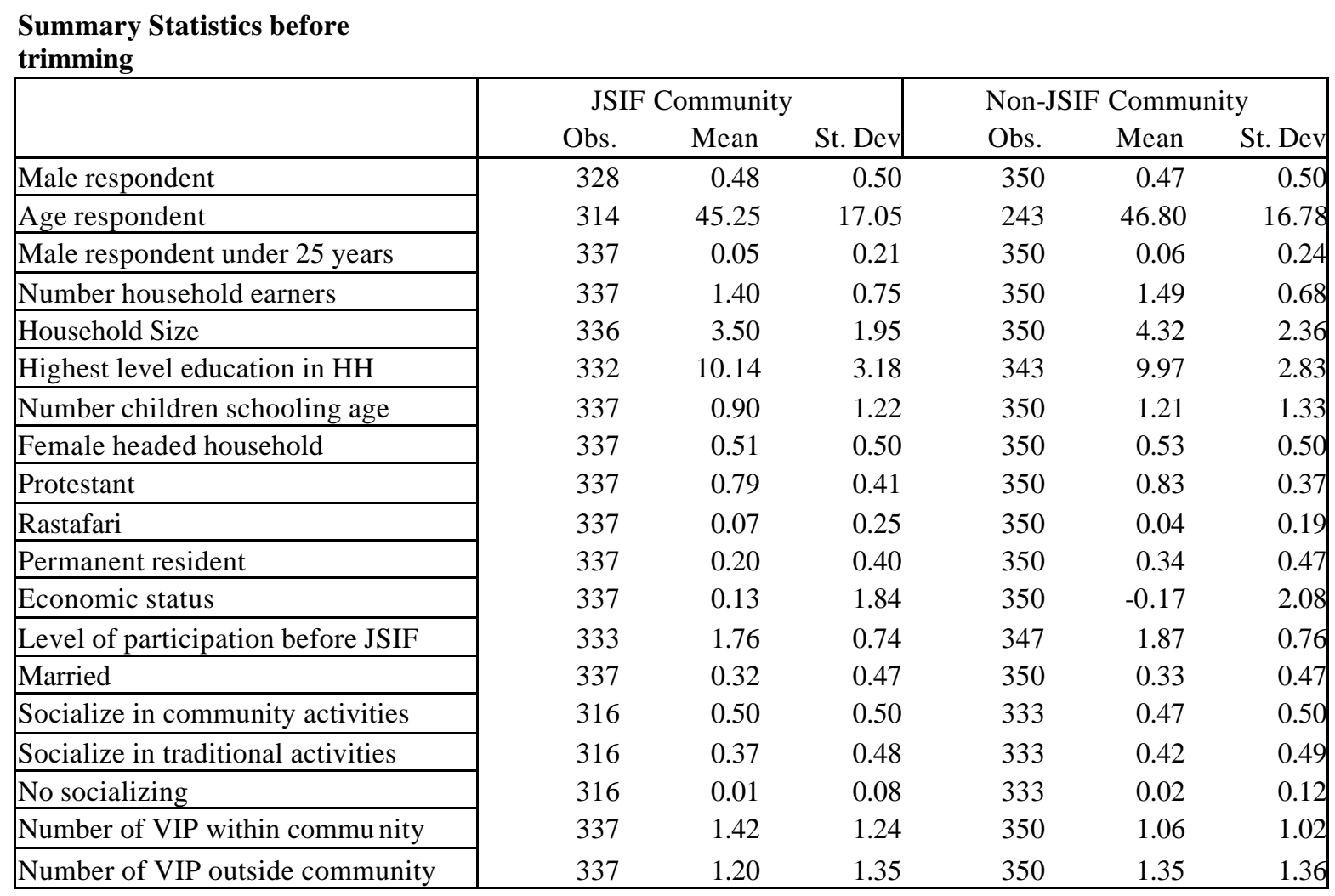

Summary Statistics after trimming

\begin{tabular}{|c|c|c|c|c|c|c|}
\hline & & mmuni & & Non-J & Commi & \\
\hline & Obs. & Mean & St. Dev & Obs. & Mean & St. Dev \\
\hline Male respondent & 291 & 0.48 & 0.50 & 320 & 0.49 & 0.50 \\
\hline Age respondent & 283 & 45.66 & 17.39 & 228 & 46.68 & 16.98 \\
\hline Male respondent under 25 years & 299 & 0.05 & 0.22 & 320 & 0.07 & 0.25 \\
\hline Number household earners & 299 & 1.43 & 0.74 & 320 & 1.50 & 0.66 \\
\hline Household Size & 299 & 3.58 & 1.96 & 320 & 4.34 & 2.41 \\
\hline Highest level education in $\mathrm{HH}$ & 299 & 10.10 & 3.19 & 320 & 9.92 & 2.84 \\
\hline Number children schooling age & 299 & 0.92 & 1.22 & 320 & 1.18 & 1.32 \\
\hline Female headed household & 299 & 0.53 & 0.50 & 320 & 0.52 & 0.50 \\
\hline Protestant & 299 & 0.81 & 0.40 & 320 & 0.84 & 0.37 \\
\hline Rastafari & 299 & 0.07 & 0.26 & 320 & 0.04 & 0.20 \\
\hline Permanent resident & 299 & 0.21 & 0.41 & 320 & 0.36 & 0.48 \\
\hline Economic status & 299 & 0.11 & 1.83 & 320 & -0.25 & 2.10 \\
\hline Level of participation before JSIF & 295 & 1.78 & 0.74 & 318 & 1.91 & 0.77 \\
\hline Married & 299 & 0.33 & 0.47 & 320 & 0.34 & 0.47 \\
\hline Socialize in community activities & 292 & 0.49 & 0.50 & 314 & 0.45 & 0.50 \\
\hline Socialize in traditional activities & 292 & 0.38 & 0.49 & 314 & 0.44 & 0.50 \\
\hline No socializing & 292 & 0.00 & 0.06 & 314 & 0.02 & 0.13 \\
\hline Number of VIP within community & 299 & 1.37 & 1.18 & 320 & 1.11 & 1.04 \\
\hline Number of VIP outside community & 299 & 1.22 & 1.35 & 320 & 1.40 & 1.37 \\
\hline
\end{tabular}




\begin{tabular}{|c|c|c|c|c|}
\hline Project: School Improvement & $\begin{array}{c}\text { SF Comm } \\
\text { Before }\end{array}$ & $\begin{array}{l}\text { nunity } \\
\text { SF }\end{array}$ & $\begin{array}{r}\text { Non-SF Cc } \\
\text { Befor }\end{array}$ & $\begin{array}{l}\text { mmunity } \\
\text { SF }\end{array}$ \\
\hline Priorities & Rank & Percent & Rank & Percent \\
\hline Income Generation & 1 & $22 \%$ & 1 & $44 \%$ \\
\hline Violence & 2 & $21 \%$ & 2 & $17 \%$ \\
\hline Health & 3 & $16 \%$ & 4 & $3 \%$ \\
\hline Lack/ low supply of water for cattle and crops & 4 & $9 \%$ & 3 & $4 \%$ \\
\hline Lack/ low supply of drinking water & 5 & $5 \%$ & NV & $\mathrm{NV}$ \\
\hline High Prices & 5 & $5 \%$ & NV & $\mathrm{NV}$ \\
\hline Education & 6 & $2 \%$ & 5 & $1 \%$ \\
\hline
\end{tabular}

Table 2a. Community Needs Before SF- Port Royal and Rennock Lodge

\begin{tabular}{|c|c|c|c|c|}
\hline Project: School improvement & $\begin{array}{r}\text { SF Comn } \\
\text { Before }\end{array}$ & $\begin{array}{l}\text { nunity } \\
\text { SF }\end{array}$ & $\begin{array}{r}\text { Non-SF Co } \\
\text { Befor }\end{array}$ & $\begin{array}{l}\text { nmunity } \\
\text { SF }\end{array}$ \\
\hline Priorities & Rank & Percent & Rank & Percent \\
\hline Lack/ low supply of drinking water & 1 & $32 \%$ & 5 & $1 \%$ \\
\hline Road & 2 & $25 \%$ & 2 & $30 \%$ \\
\hline Lack of credit facilities & 2 & $25 \%$ & 2 & $30 \%$ \\
\hline Income Generation & 3 & $16 \%$ & 1 & $46 \%$ \\
\hline Education & 4 & $4 \%$ & 3 & $4 \%$ \\
\hline Lack of telephones & 4 & $4 \%$ & $\mathrm{NV}$ & $\mathrm{NV}$ \\
\hline Lighting system & 4 & $4 \%$ & $\mathrm{NV}$ & NV \\
\hline
\end{tabular}

Table 2b. Community Needs before - Virginia and Downing

\begin{tabular}{|l|r|r|}
\hline Project: School Improvement & \multicolumn{2}{|c|}{$\begin{array}{c}\text { SF Community } \\
\text { Before SF } \\
\text { Rank }\end{array}$} \\
Priorities & 1 & $23 \%$ \\
\hline Credit Facilities & 1 & $23 \%$ \\
\hline Lack/ low supply of drinking water & 2 & $18 \%$ \\
\hline Lack/ low supply of water for cattle and crops & 3 & $14 \%$ \\
\hline Income Generation & 4 & $\mathbf{7 \%}$ \\
\hline Lighting system & $\mathbf{5}$ & $\mathbf{2 \%}$ \\
\hline Education & & \\
\hline
\end{tabular}

Table 2c. Community Needs before SF- Rock Creek

Table 2d. Community Needs before SF- Arnett Gardens and Union Gardens

\begin{tabular}{|l|r|r|r|r|}
\hline Project: Stadium renovation & \multicolumn{2}{|c|}{$\begin{array}{l}\text { SF Community } \\
\text { Before SF } \\
\text { Priorities }\end{array}$} & \multicolumn{2}{|c|}{$\begin{array}{c}\text { Non-SF Community } \\
\text { Before SF } \\
\text { Rank }\end{array}$} \\
\hline Violence & $\mathbf{1}$ & $\mathbf{5 8 \%}$ & $\mathbf{2}$ & $\mathbf{1 4 \%}$ \\
\hline Income Generation & 2 & $16 \%$ & 1 & $52 \%$ \\
\hline Arguments in the community & 3 & $8 \%$ & 5 & $1 \%$ \\
\hline Lack of leadership & 4 & $5 \%$ & 3 & $4 \%$ \\
\hline Lack/ low supply of drinking water & 4 & $5 \%$ & $\mathrm{NV}$ & $\mathrm{NV}$ \\
\hline Education & 6 & $3 \%$ & 4 & $3 \%$ \\
\hline
\end{tabular}




\begin{tabular}{|l|r|r|r|r|}
\hline Project: Road Improvement & \multicolumn{3}{|c|}{$\begin{array}{l}\text { SF Community } \\
\text { Before SF }\end{array}$} & \multicolumn{2}{c|}{$\begin{array}{c}\text { Non-SF Community } \\
\text { Before SF } \\
\text { Priorities }\end{array}$} & Rank & Percent & Rank \\
\hline Road & $\mathbf{1}$ & $\mathbf{3 9 \%}$ & $\mathbf{2}$ & $\mathbf{3 1 \%}$ \\
\hline Lack/ low supply of drinking water & 2 & $34 \%$ & 1 & $41 \%$ \\
\hline Income Generation & 3 & $8 \%$ & 5 & $5 \%$ \\
\hline Lack/ low supply of water for cattle and crops & 4 & $5 \%$ & 3 & $14 \%$ \\
\hline Violence & 5 & $3 \%$ & $\mathrm{NV}$ & $\mathrm{NV}$ \\
\hline
\end{tabular}

Table 2e. Community Needs before SF- New Valley/Orange and Shadow/California 
Table 3

Did you have a meeting to decide about the project?

\begin{tabular}{|l|c|}
\hline & JSIF \\
\hline Yes & $59.2(125)$ \\
\hline Total & $100.0(211)$ \\
\hline
\end{tabular}

Probit Regression

\begin{tabular}{|l|rr|}
\hline Variables & Marginal & t-statistic \\
\cline { 1 - 1 } Male respondent & 0.08080 & 0.75 \\
\cline { 1 - 1 } Age respondent & -0.02590 & -1.33 \\
\cline { 1 - 1 } Age respondent squared & 0.00035 & 1.67 \\
\cline { 1 - 1 } Male respondent under 25 years & -0.17608 & -0.67 \\
\cline { 1 - 1 } Number household earners & 0.13174 & 1.70 \\
\cline { 1 - 1 } Household Size & 0.02947 & 0.71 \\
\cline { 1 - 1 } Highest level education in HH & 0.00647 & 0.36 \\
\cline { 1 - 1 } Number children schooling age & 0.01424 & 0.22 \\
\cline { 1 - 1 } Female headed household & 0.02559 & 0.23 \\
\cline { 1 - 1 } Protestant & -0.27294 & -2.33 \\
\cline { 1 - 1 } Rastafari & -0.11036 & -0.50 \\
\cline { 1 - 1 } Permanent resident & 0.18852 & 1.64 \\
\cline { 1 - 1 } New Valley-Orange/Shadow-California & -0.40260 & -2.54 \\
\cline { 1 - 1 } Port Royal/Kennock & -0.30973 & -1.64 \\
\cline { 1 - 1 } Arnette Gardens/Union Gardens & -0.70637 & -4.90 \\
\cline { 1 - 1 } Rock Creek/Creighton & -0.53721 & -3.11 \\
\cline { 1 - 1 } Economic status & -0.05251 & -1.57 \\
\cline { 1 - 1 } Level of participation before JSIF & 0.13390 & 1.94 \\
\cline { 1 - 1 } Married & 0.02429 & 0.23 \\
\cline { 1 - 1 } Socialize in community activities & 0.02815 & 0.17 \\
\cline { 1 - 1 } Socialize in traditional activities & -0.09047 & -0.51 \\
\cline { 1 - 1 } Number of VIP within community & 0.07251 & 1.64 \\
\cline { 1 - 1 } Number of VIP outside community & 0.02110 & 0.54 \\
\cline { 1 - 1 } Number of observations & & 194 \\
Wald test & & 98.07 \\
Pseudo R-square & & 0.372 \\
\hline
\end{tabular}


Table 4

Participation in Social Fund Meeting - Probit Regression

\begin{tabular}{|c|c|c|}
\hline Variables & Marginal & t-statistic \\
\hline Male respondent & 0.093255 & 1.48 \\
\hline Age respondent & 0.003055 & 0.38 \\
\hline Age respondent squared & -0.000010 & -0.14 \\
\hline Male respondent under 25 years & 0.086185 & 0.52 \\
\hline Number household earners & -0.018708 & -0.48 \\
\hline Household Size & 0.031997 & 1.38 \\
\hline Highest level education in $\mathrm{HH}$ & -0.005635 & -0.57 \\
\hline Number children schooling age & -0.014043 & -0.42 \\
\hline Female headed household & -0.002901 & -0.05 \\
\hline Protestant & -0.011797 & -0.14 \\
\hline Rastafari & 0.097109 & 0.64 \\
\hline Permanent resident & 0.123033 & 1.79 \\
\hline New Valley-Orange/Shadow-California & -0.023791 & -0.29 \\
\hline Port Royal/Kennock & -0.117366 & -1.33 \\
\hline Arnette Gardens/Union Gardens & -0.203641 & -2.5 \\
\hline Rock Creek/Creighton & -0.152942 & -1.84 \\
\hline Economic status & -0.026820 & -1.45 \\
\hline Level of participation before JSIF & 0.080577 & 2.04 \\
\hline Married & 0.047801 & 0.8 \\
\hline Socialize in community activities & 0.140674 & 1.32 \\
\hline Socialize in traditional activities & 0.025144 & 0.21 \\
\hline Number of VIP within community & 0.068108 & 2.75 \\
\hline Number of VIP outside community & 0.041601 & 2.03 \\
\hline Number of observations & & 297 \\
\hline Wald test & & 73.34 \\
\hline Pseudo R-square & & 0.254 \\
\hline
\end{tabular}


Table 5

Did the SF Project Address the Main Problems of the Community?

\begin{tabular}{|l|r|}
\hline & \multicolumn{1}{c|}{ JSIF } \\
\hline Did not address any problem & $73.0(246)$ \\
\hline Project addressed third main problem & $3.8(13)$ \\
\hline Project addressed second main problem & $9.2(31)$ \\
\hline Project addressed first main problem & $14.0(47)$ \\
\hline Total & $100.0(337)$ \\
\hline
\end{tabular}

\section{Ordered Probit}

\begin{tabular}{|l|rr|}
\hline Variables & Coefficient & t-statistic \\
\hline Male respondent & -0.0617 & -0.284 \\
\cline { 1 - 1 } Age respondent & -0.0291 & -1.112 \\
\cline { 1 - 1 } Age respondent squared & 0.0003 & 1.191 \\
\cline { 1 - 1 } Male respondent under 25 years & 0.2572 & 1.914 \\
\cline { 1 - 1 } Number household earners & -0.2309 & -3.332 \\
\cline { 1 - 1 } Household Size & 0.0807 & 2.233 \\
\cline { 1 - 1 } Highest level education in HH & 0.2758 & 2.397 \\
\cline { 1 - 1 } Number children schooling age & 0.2314 & 1.061 \\
\cline { 1 - 1 } Female headed household & 0.1195 & 0.439 \\
\cline { 1 - 1 } Protestant & 0.2173 & 0.564 \\
\cline { 1 - 1 } Rastafari & 0.1666 & 0.547 \\
\cline { 1 - 1 } Permanent resident & -0.1162 & -0.335 \\
\cline { 1 - 1 } New Valley-Orange/Shadow-California & 0.2110 & 0.524 \\
Port Royal/Kennock & 2.6691 & 7.159 \\
\cline { 1 - 1 } Arnette Gardens/Union Gardens & -0.5849 & -1.458 \\
\cline { 1 - 1 } Rock Creek/Creighton & -0.0689 & -1.027 \\
\cline { 1 - 1 } Economic status & 0.0950 & 0.726 \\
\cline { 1 - 1 } Level of participation before JSIF & 0.2221 & 1.008 \\
\cline { 1 - 1 } Married & 0.1355 & 0.462 \\
\cline { 1 - 1 } Socialize in community activities & 0.3170 & 1.016 \\
\cline { 1 - 1 } Socialize in traditional activities & -0.1472 & -0.318 \\
\cline { 1 - 1 } Number of VIP within community & 0.0269 & 0.289 \\
\cline { 1 - 1 } Number of VIP outside community & -0.1192 & -1.348 \\
\hline Number of observations & & 299 \\
Wald test & & 206.08 \\
Pseudo R-square & & 0.3744 \\
\hline
\end{tabular}


Table 6

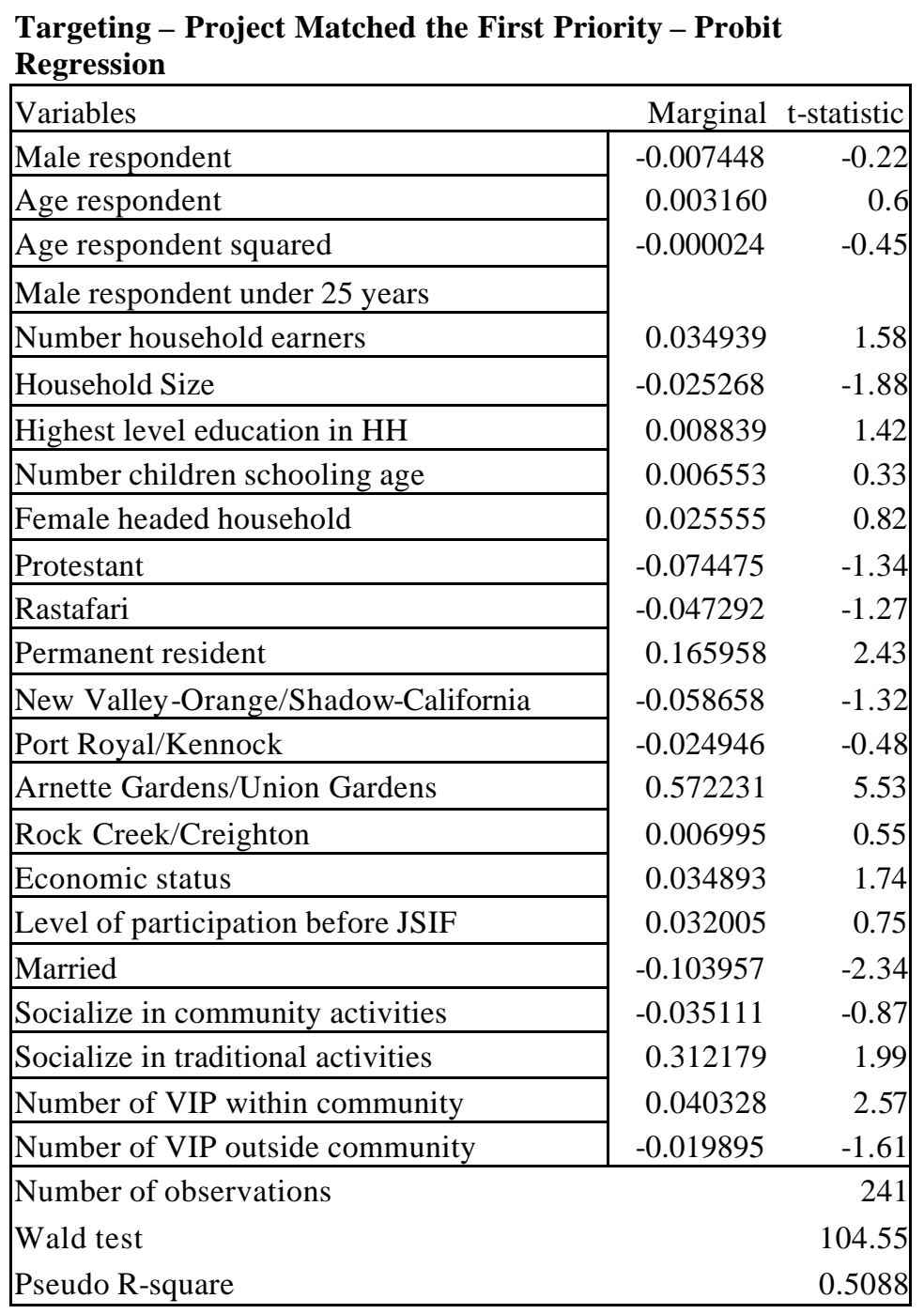


Table 7

Would you have preferred Another Project?

\begin{tabular}{|l|c|}
\hline \multicolumn{2}{|c|}{ JSIF } \\
\hline No & $82.4 \quad(174)$ \\
\hline Yes & $17.57(37)$ \\
\hline Total & $100.0(211)$ \\
\hline
\end{tabular}

Probit - Regression

\begin{tabular}{|c|c|c|}
\hline Variables & Coefficient & t-statistic \\
\hline Male respondent & 0.0131 & 0.21 \\
\hline Age respondent & -0.0005 & -0.05 \\
\hline Age respondent squared & -0.0000 & -0.05 \\
\hline Male respondent under 25 years & 0.0375 & 0.24 \\
\hline Number household earners & -0.3254 & -0.77 \\
\hline Household Size & 0.0079 & 0.33 \\
\hline Highest level education in $\mathrm{HH}$ & 0.0059 & 0.55 \\
\hline Number children schooling age & -0.0161 & 0.39 \\
\hline Female headed household & 0.0548 & 0.81 \\
\hline Protestant & -0.1268 & -1.45 \\
\hline Rastafari & 0.0572 & 0.41 \\
\hline Permanent resident & -0.1269 & -2.04 \\
\hline New Valley-Orange/Shadow-California & 0.0224 & 0.27 \\
\hline Port Royal/Kennock & 0.1773 & 1.37 \\
\hline Arnette Gardens/Union Gardens & -0.0810 & -0.98 \\
\hline Rock Creek/Creighton & -0.0260 & -0.38 \\
\hline Economic status & -0.0261 & 1.33 \\
\hline Level of participation before JSIF & 0.0302 & 0.74 \\
\hline Married & 0.4171 & 0.67 \\
\hline Socialize in community activities & -0.3170 & -0.75 \\
\hline Socialize in traditional activities & -0.4620 & -0.51 \\
\hline Number of VIP within community & 0.0036 & 0.14 \\
\hline Number of VIP outside community & -0.0051 & -0.22 \\
\hline Number of observations & & 194 \\
\hline Wald test & & 22.49 \\
\hline Pseudo R-square & & 0.12 \\
\hline
\end{tabular}


Table 8

Propensity Score

\begin{tabular}{|c|c|c|}
\hline Variables & Marginal & t-statistic \\
\hline Male respondent & -0.0841638 & -0.8 \\
\hline Age respondent & 0.0086509 & \\
\hline Age respondent squared & -0.0000692 & -0. \\
\hline Male respondent under 25 years & 0.0391364 & \\
\hline Number household earners & -0.0128123 & -0. \\
\hline Household Size & -0.0631853 & -3. \\
\hline Highest level education in $\mathrm{HH}$ & 0.0187891 & 1.5 \\
\hline Number children schooling age & 0.0501981 & 1.5 \\
\hline Female headed household & -0.0476699 & -0. \\
\hline Protestant & -0.1001048 & -1. \\
\hline Rastafari & -0.0522881 & -0.4 \\
\hline Permanent resident & -0.1186874 & \\
\hline New Valley-Orange/Shadow-California & -0.2819047 & -4.2 \\
\hline Port Royal/Kennock & -0.2224293 & -2.5 \\
\hline Arnette Gardens/Union Gardens & -0.1989795 & -2.2 \\
\hline Rock Creek/Creighton & -0.0430962 & -0.5 \\
\hline Economic status & -0.0011797 & -0.0 \\
\hline Level of participation before JSIF & -0.1082521 & -3. \\
\hline Married & 0.0413458 & 0.7 \\
\hline Socialize in community activities & -0.0374556 & -0.4 \\
\hline Socialize in traditional activities & -0.0603422 & $-0 .($ \\
\hline No socializing & -0.3472967 & -1.3 \\
\hline Number of VIP within community & 0.0638849 & 2.5 \\
\hline Number of VIP outside community & -0.0325901 & -1.5 \\
\hline \multicolumn{2}{|l|}{ Number of observations } & 4 \\
\hline \multicolumn{2}{|l|}{ Wald test } & 70.5 \\
\hline \multicolumn{2}{|l|}{ Pseudo R-square } & 0.118 \\
\hline
\end{tabular}


Table 9

Is it easier now to work with groups and associations of people outside the immediate household?

"Difference in Difference" Cross-Tabulations

\begin{tabular}{|c|c|c|}
\hline & JSIF & Non-JSIF \\
\hline Very Difficult & $7.48(22)$ & $7.01(22)$ \\
\hline Difficult & $13.61(40)$ & $24.84(78)$ \\
\hline Same & $21.77(64)$ & $20.06(63)$ \\
\hline Easy & $37.76(111)$ & $38.85(122)$ \\
\hline Very Easy & $19.39(57)$ & $9.24(29)$ \\
\hline Total & 100.00 (294) & $100.00(314)$ \\
\hline
\end{tabular}

Pearson Chi-Square: 21.2458

\section{Nearest Neighbor Estimates}

Differences

\begin{tabular}{|l|l|}
\hline Nearest neighbor & \\
\hline
\end{tabular}

\begin{tabular}{|l|r|}
\hline Mean & 0.33 \\
\hline t-statistic $^{1}$ & 4.83 \\
\hline
\end{tabular}

\begin{tabular}{|l|l|}
\hline Age $^{2}$ & 4.83 \\
\hline
\end{tabular}

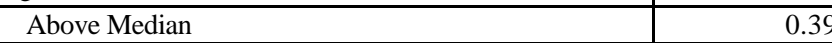

\begin{tabular}{|c|c} 
Below Median & 0.28 \\
\hline
\end{tabular}

\begin{tabular}{l|r} 
Test Difference Equal Zero & 0.80 \\
\hline
\end{tabular}

\begin{tabular}{|c|r|}
\hline Economic Status $^{3}$ & \\
\hline Above Median & 0.47 \\
\hline
\end{tabular}

\begin{tabular}{|l|l|}
\hline Below Median & 0.19 \\
\hline Test Difference Equal Zero & 2.04 \\
\hline
\end{tabular}

\begin{tabular}{|l|r|}
\hline Education $^{4}$ & \\
\hline Above Median & 0.43 \\
\hline Below Median & 0.27
\end{tabular}

\begin{tabular}{|l|r|}
\hline Above Median & 0.43 \\
\hline Below Median & 0.27 \\
\hline Test Difference Equal Zero & 1.14 \\
\hline
\end{tabular}

\begin{tabular}{|c|r|}
\hline Gender & \\
\hline Female & 0.32 \\
\hline
\end{tabular}

\begin{tabular}{|l|r|}
\hline Female & 0.32 \\
\hline Male & 0.34 \\
\hline
\end{tabular}

\begin{tabular}{|l|r|}
\hline Test Difference Equal Zero & -0.12 \\
\hline
\end{tabular}

\begin{tabular}{|c|c|}
\hline Religious Preference & \\
\hline Non-Protestant & 0.18 \\
\hline
\end{tabular}

\begin{tabular}{|l|r|}
\hline Non-Protestant & 0.18 \\
\hline Protestant & 0.37 \\
\hline
\end{tabular}

\begin{tabular}{|l|r|}
\hline Test Difference Equal Zero & -1.12 \\
\hline
\end{tabular}

\begin{tabular}{|c|r|}
\hline Labor Status & \\
\hline Employed & 0.35 \\
\hline
\end{tabular}

\begin{tabular}{|l|r|}
\hline Employed & 0.35 \\
\hline Unemployed & 0.13 \\
\hline
\end{tabular}

\begin{tabular}{|r|r|}
\hline Test Difference Equal Zero & 0.90 \\
\hline
\end{tabular}

Married

\begin{tabular}{|l|r|}
\hline Non-Married & 0.31 \\
\hline Married & 0.39 \\
\hline Test Difference Equal Zero & -0.49 \\
\hline VIPs within community & \\
\hline Above Median & 0.38 \\
\hline Below Median & 0.30 \\
\hline Test Difference Equal Zero & 0.57 \\
\hline VIPs outside community & \\
\hline Above Median & 0.30 \\
\hline Below Median & 0.35 \\
\hline Test Difference Equal Zero & -0.32 \\
\hline
\end{tabular}

${ }^{1}$ Bootstrapped standard errors

${ }^{2}$ The median for age is 42 years

${ }^{3}$ The median for economic status is 0.36

${ }^{4}$ The median for years of education is 11 
Table 10

\section{Trust in the Community}

"Difference in Difference" Cross-Tabulations

\begin{tabular}{|l|r|r|}
\hline & \multicolumn{1}{c|}{ JSIF } & \multicolumn{1}{c|}{ Non-JSIF } \\
\hline Worse & $18.09(53)$ & $28.34(89)$ \\
\hline Same & $35.15(103)$ & $33.79(106)$ \\
\hline Better & $46.76(137)$ & $37.90(119)$ \\
\hline Total & $100.00(293)$ & $100.00(314)$ \\
\hline
\end{tabular}

Pearson ChiSquare: 21.2458

Nearest Neighbor Estimates

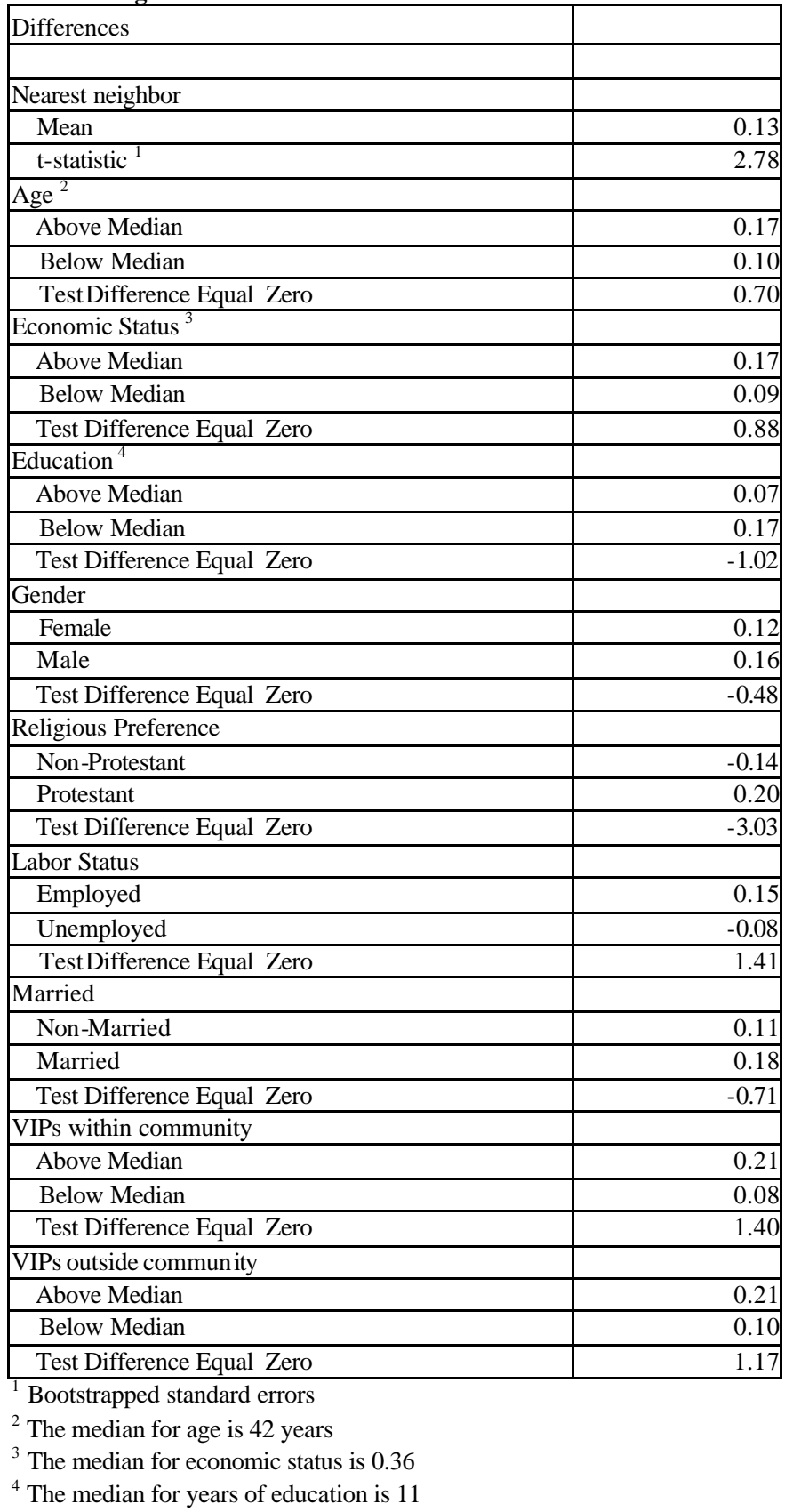


Table 11

\section{Easy to reach agreements}

\section{"Difference in Difference" Cross-Tabulations}

\begin{tabular}{|l|r|r|}
\hline & \multicolumn{1}{c|}{ JSIF } & \multicolumn{1}{c|}{ Non-JSIF } \\
\hline Very Difficult & $11.50(33)$ & $6.21(19)$ \\
\hline Difficult & $15.33(44)$ & $30.07(92)$ \\
\hline Same & $21.25(61)$ & $17.65(54)$ \\
\hline Easy & $34.15(98)$ & $24.18(74)$ \\
\hline Very Easy & $17.77(51)$ & $21.90(67)$ \\
\hline Total & $100.00(287)$ & $100.00(306)$ \\
\hline
\end{tabular}

Pearson ChiSquare: 26.0728

\section{Nearest Neighbor Estimates}

Differences

\begin{tabular}{|c|c|}
\hline Differences & \\
\hline Nearest neighbor & \\
\hline Mean & 0.06 \\
\hline t-statistic ${ }^{1}$ & 0.83 \\
\hline Age $^{2}$ & \\
\hline Above Median & 0.15 \\
\hline Below Median & -0.01 \\
\hline Test Difference Equal Zero & 1.06 \\
\hline Economic Status $^{3}$ & \\
\hline Above Median & 0.13 \\
\hline Below Median & 0.00 \\
\hline Test Difference Equal Zero & 0.88 \\
\hline Education $^{4}$ & \\
\hline Above Median & 0.00 \\
\hline Below Median & 0.10 \\
\hline Test Difference Equal Zero & -0.66 \\
\hline Gender & \\
\hline Female & 0.13 \\
\hline Male & 0.04 \\
\hline Test Difference Equal Zero & 0.60 \\
\hline Religious Preference & \\
\hline Non-Protestant & -0.10 \\
\hline Protestant & 0.11 \\
\hline Test Difference Equal Zero & -1.10 \\
\hline Labor Status & \\
\hline Employed & 0.11 \\
\hline Unemployed & -0.48 \\
\hline Test Difference Equal Zero & 2.27 \\
\hline Married & \\
\hline Non-Married & 0.08 \\
\hline Married & 0.04 \\
\hline Test Difference Equal Zero & 0.23 \\
\hline VIPs within community & \\
\hline Above Median & 0.21 \\
\hline Below Median & -0.05 \\
\hline Test Difference Equal Zero & 1.76 \\
\hline VIPs outside community & \\
\hline Above Median & 0.21 \\
\hline Below Median & 0.00 \\
\hline Test Difference Equal Zero & 1.23 \\
\hline
\end{tabular}

${ }^{1}$ Bootstrapped standard errors

${ }^{2}$ The median for age is 42 years

${ }^{3}$ The median for economic status is 0.36

${ }^{4}$ The median for years of education is 11 
Table 12

\section{Community Leader Responsiveness}

"Difference in Difference" Cross-Tabulations

\begin{tabular}{|l|r|r|}
\hline \multicolumn{1}{|c|}{ JSIF } & \multicolumn{1}{c|}{ Non-JSIF } \\
\hline No & $74.24(219)$ & $75.00(240)$ \\
\hline Yes & $25.76(76)$ & $25.00(80)$ \\
\hline Total & $100.00(295)$ & $100.00(320)$ \\
\hline
\end{tabular}

Pearson Chi-Square: 0.0472

Nearest Neighbor Estimates

\begin{tabular}{|c|c|}
\hline \multicolumn{2}{|l|}{ Differences } \\
\hline \multicolumn{2}{|l|}{ Nearest neighbor } \\
\hline Mean & 0.01 \\
\hline t-statistic ${ }^{1}$ & 0.21 \\
\hline \multicolumn{2}{|l|}{$\mathrm{Age}^{2}$} \\
\hline Above Median & -0.09 \\
\hline Below Median & 0.09 \\
\hline Test Difference Equal Zero & -2.80 \\
\hline \multicolumn{2}{|l|}{ Economic Status $^{3}$} \\
\hline Above Median & 0.03 \\
\hline Below Median & -0.02 \\
\hline Test Difference Equal Zero & 0.76 \\
\hline \multicolumn{2}{|l|}{ Education $^{4}$} \\
\hline Above Median & 0.05 \\
\hline Below Median & -0.02 \\
\hline Test Difference Equal Zero & 1.14 \\
\hline \multicolumn{2}{|l|}{ Gender } \\
\hline Female & -0.02 \\
\hline Male & 0.04 \\
\hline Test Difference Equal Zero & -1.00 \\
\hline \multicolumn{2}{|l|}{ Religious Preference } \\
\hline Non-Protestant & -0.07 \\
\hline Protestant & 0.02 \\
\hline Test Difference Equal Zero & -1.19 \\
\hline \multicolumn{2}{|l|}{ Labor Status } \\
\hline Employed & $\overline{0.00}$ \\
\hline Unemployed & 0.02 \\
\hline Test Difference Equal Zero & -0.15 \\
\hline \multicolumn{2}{|l|}{ Married } \\
\hline Non-Married & 0.05 \\
\hline Married & -0.08 \\
\hline Test Difference Equal Zero & 1.85 \\
\hline \multicolumn{2}{|l|}{ VIPs within community } \\
\hline Above Median & 0.05 \\
\hline Below Median & -0.03 \\
\hline Test Difference Equal Zero & 1.32 \\
\hline \multicolumn{2}{|l|}{ VIPs outside community } \\
\hline Above Median & 0.09 \\
\hline Below Median & -0.03 \\
\hline Test Difference Equal Zero & 1.71 \\
\hline
\end{tabular}

${ }^{1}$ Bootstrapped standard errors

${ }^{2}$ The median for age is 42 years

${ }^{3}$ The median for economic status is 0.36

${ }^{4}$ The median for years of education is 11 
Table 13

\section{Decisions by Community Leader}

"Difference in Difference" Cross-Tabulations

\begin{tabular}{|l|r|r|}
\hline & \multicolumn{1}{c|}{ JSIF } & \multicolumn{1}{c|}{ Non-JSIF } \\
\hline Less Now & $19.29(27)$ & $28.57(64)$ \\
\hline Same Now & $26.43(37)$ & $29.91(67)$ \\
\hline More Now & $54.29(76)$ & $41.52(93)$ \\
\hline Total & $100.00(140)$ & $100.00(224)$ \\
\hline
\end{tabular}

Pearson ChiSquare: 6.3621

Nearest Neighbor Estimates

\begin{tabular}{|c|c|}
\hline \multicolumn{2}{|l|}{ Differences } \\
\hline \multicolumn{2}{|l|}{ Nearest neighbor } \\
\hline Mean & 0.18 \\
\hline t-statist ic ${ }^{1}$ & 2.68 \\
\hline \multicolumn{2}{|l|}{ Age $^{2}$} \\
\hline Above Median & 0.31 \\
\hline Below Median & 0.08 \\
\hline Test Difference Equal Zero & 1.74 \\
\hline \multicolumn{2}{|l|}{ Economic Status $^{3}$} \\
\hline Above Median & 0.11 \\
\hline Below Median & 0.25 \\
\hline Test Difference Equal Zero & -1.05 \\
\hline \multicolumn{2}{|l|}{ Education $^{4}$} \\
\hline Above Median & 0.01 \\
\hline Below Median & 0.28 \\
\hline Test Difference Equal Zero & -2.02 \\
\hline \multicolumn{2}{|l|}{ Gender } \\
\hline Female & 0.24 \\
\hline Male & 0.10 \\
\hline Test Difference Equal Zero & 1.11 \\
\hline \multicolumn{2}{|l|}{ Religious Preference } \\
\hline Non-Protestant & -0.03 \\
\hline Protestant & 0.24 \\
\hline Test Difference Equal Zero & -1.75 \\
\hline \multicolumn{2}{|l|}{ Labor Status } \\
\hline Employed & 0.20 \\
\hline Unemployed & 0.00 \\
\hline Test Difference Equal Zero & 0.89 \\
\hline \multicolumn{2}{|l|}{ Married } \\
\hline Non-Married & 0.11 \\
\hline Married & 0.33 \\
\hline Test Difference Equal Zero & -1.60 \\
\hline \multicolumn{2}{|l|}{ VIPs within community } \\
\hline Above Median & 0.19 \\
\hline Below Median & 0.16 \\
\hline Test Difference Equal Zero & 0.21 \\
\hline \multicolumn{2}{|l|}{ VIPs outside community } \\
\hline Above Median & 0.18 \\
\hline Below Median & 0.18 \\
\hline Test Difference Equal Zero & -0.03 \\
\hline
\end{tabular}

Bootstrapped standard errors

${ }^{2}$ The median for age is 42 years

${ }^{3}$ The median for economic status is 0.36

${ }^{4}$ The median for years of education is 11 
Table 14

\section{Decisions by Community Meeting with Vote}

"Difference in Difference" Cross-Tabulations

\begin{tabular}{|l|r|r|}
\hline & \multicolumn{1}{c|}{ JSIF } & \multicolumn{1}{c|}{ Non-JSIF } \\
\hline Less Now & $21.26(27)$ & $28.88(54)$ \\
\hline Same Now & $28.35(36)$ & $24.06(45)$ \\
\hline More Now & $50.39(64)$ & $47.06(88)$ \\
\hline Total & $100.00(127)$ & $100.00(187)$ \\
\hline
\end{tabular}

Pearson Chi-Square: 2.4126

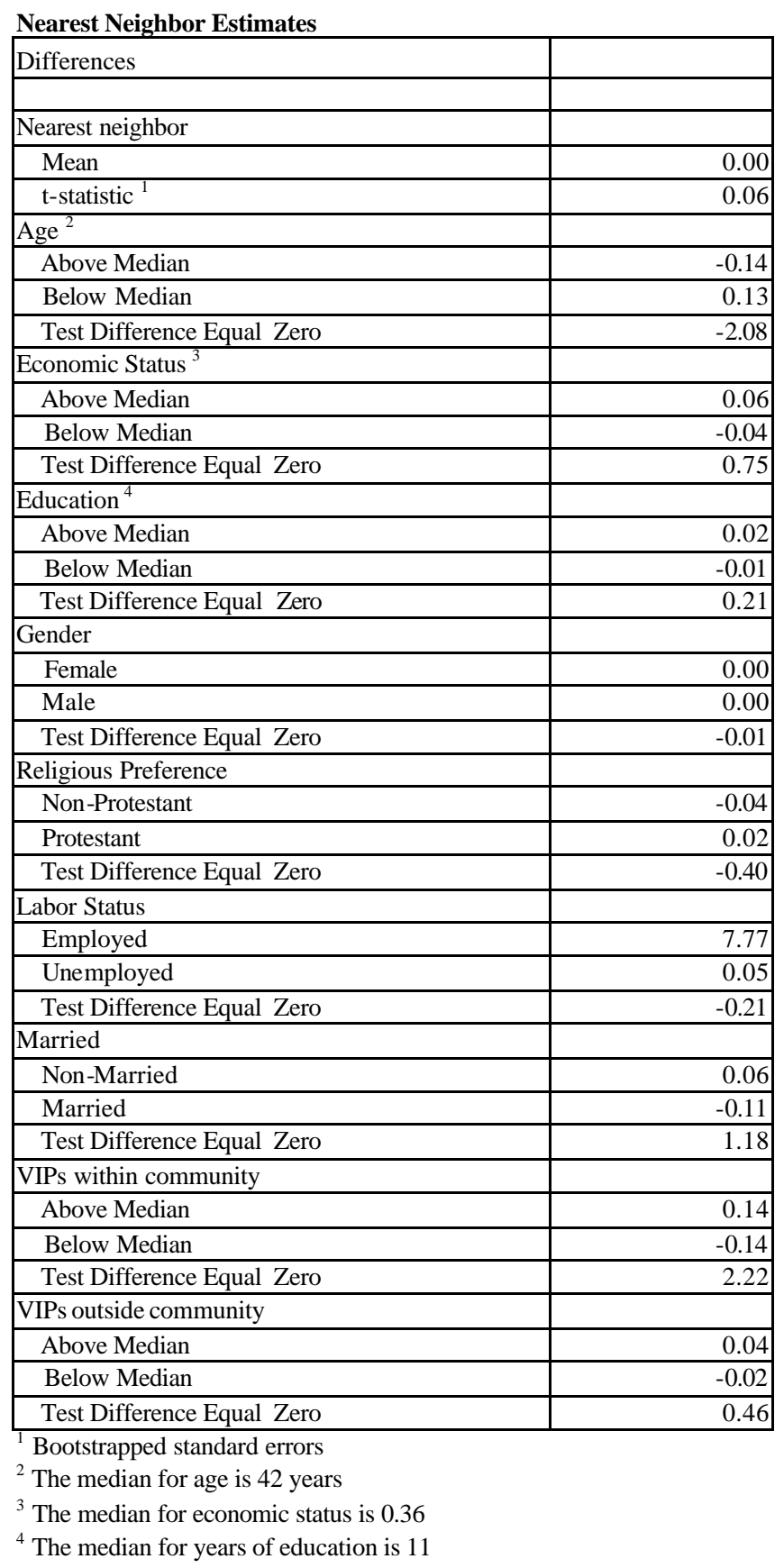

